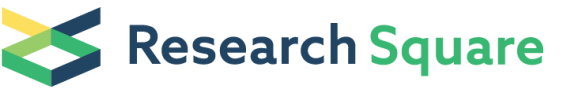

\section{Applying Hybrid Equal Channel Angular Pressing (HECAP) to pure copper using optimized Exp.-ECAP die}

\section{Serkan Öğüt ( $\sim$ serkan.ogut@marmara.edu.tr )}

Marmara Universitesi - Goztepe Kampusu: Marmara Universitesi

Hasan Kaya

Kocaeli University

Aykut Kentli

Marmara University

Mehmet UÇAR

Kocaeli University

\section{Research Article}

Keywords: Pure Copper, Mechanical Properties, Microstructure, SPD, ECAP, Exp.-ECAP

Posted Date: April 7th, 2021

DOl: https://doi.org/10.21203/rs.3.rs-371053/v1

License: (c) (i) This work is licensed under a Creative Commons Attribution 4.0 International License. Read Full License

Version of Record: A version of this preprint was published at The International Journal of Advanced Manufacturing Technology on July 24th, 2021. See the published version at https://doi.org/10.1007/s00170-021-07717-9. 


\title{
Applying Hybrid Equal Channel Angular Pressing (HECAP) to pure copper using optimized Exp.-ECAP die
}

\author{
Serkan Öğüt ${ }^{1, *}$, Hasan Kaya ${ }^{2}$, Aykut Kentli ${ }^{1}$, Mehmet Uçar ${ }^{3}$ \\ ${ }^{1}$ Marmara University, Faculty of Engineering, Mechanical Engineering Department, İstanbul, Turkey \\ *Corresponding author: serkan.ogut@marmara.edu.tr \\ ${ }^{2}$ Kocaeli University, Hereke Asım Kocabıyık Vocational School, Machine and Metal Technology \\ Department, Kocaeli, Turkey \\ ${ }^{3}$ Kocaeli University, Faculty of Technology, Automotive Engineering Department, Kocaeli, Turkey
}

\begin{abstract}
Equal channel angular pressing (ECAP), expansion equal channel angular pressing (Exp.-ECAP) and hybrid equal channel angular pressing (HECAP) processes were applied to pure copper specimens within this study. Before the ECAP and HECAP processes, an Exp.-ECAP mold with optimum geometric parameters was produced to be used in these processes. The samples, on which ECAP, Exp.ECAP and HECAP processes were applied, were subjected to microstructure analysis and mechanical tests, and the effects of these processes were examined. The results obtained showed that the Exp.-ECAP process gave better results in grain refinement and mechanical properties, and the Exp.-ECAP passes applied after the ECAP process within the scope of the HECAP process provided a more homogeneous distribution for grain size and hardness.
\end{abstract}

Keywords: Pure Copper, Mechanical Properties, Microstructure, SPD, ECAP, Exp.-ECAP

\section{Introduction}

Severe plastic deformation (SPD) is one of the important grain refinement processes preferred by researchers. Thanks to SPD processes, ultra-fine grained (UFG) materials can be obtained. The reason why SPD methods are preferred as grain refinement methods is that they do not cause any change in the external dimensions of the specimen during the process and thus the process can be continued repeatedly. Although there are many SPD processes such as high pressure torsion (HPT)[1], multidirectional forging (MDF)[2], twist extrusion (TE)[3], repetitive corrugation and straightening (RCS)[4] and accumulative roll-bonding (ARB)[5], the most preferred SPD process is the equal channel angular pressing (ECAP) [6-8] process. This is because the ECAP method is a process that provides large effective strain and does not require a complex and expensive experimental setup. In recent years, studies proposing certain modifications to the process have been carried out to increase the efficiency of the ECAP process and to expand its application areas. As a result of these studies, many modified ECAP processes such as tubular channel angular pressing (TCAP) [9], incremental equal channel angular pressing (I-ECAP)[10], thin-walled open channel angular pressing (TWO-CAP)[11, 12], and ECAPConform have been added to the literature. Expansion equal channel angular extrusion (Exp.-ECAE)[13] or expansion equal channel angular pressing (Exp.-ECAP) is one of the modified ECAP processes. The biggest difference in the die designed for this process compared to the classical ECAP die is that there is a spherical cavity which leads to pseudo-back pressure being exerted on the specimen during the process. In this way, a more homogeneous effective plastic strain distribution is obtained on the specimen, and higher strain values can be obtained thanks to the extrusion ratio between the spherical cavity and channels. Pure copper is a metal with high electrical conductivity and thermal conductivity properties, but it cannot be said to have high values in terms of mechanical properties. For this reason, it is a preferred metal in many SPD works[14-20]. Although the Exp.-ECAP process has been applied for some aluminum and magnesium alloys[13, 21, 22], it has not been applied before for pure copper. 
In this study, pure copper was subjected to ECAP and Exp.-ECAP processes. In addition, a process called hybrid equal channel angular pressing (HECAP), which consists of the combination of ECAP and Exp-ECAP process, was applied to pure copper. With this application, the effects of the Exp.-ECAP process applied to an ECAP applied specimen were investigated. In addition, the Exp.-ECAP die was optimized within the scope of this study and this optimized die was used in the Exp.-ECAP and HECAP processes.

\section{Material and Method}

The methodology applied within the scope of the study consists of several steps. Firstly, the ECAP process was subjected to copper specimens. Secondly, a finite element (FE) model was generated for the ECAP process and validated by comparing load-displacement curves obtained from the experiment and finite element analysis (FEA). After validating the FE model generated for the ECAP process, another FE model was generated for the Exp.-ECAP process using the same boundary conditions used in the ECAP FE model. In the next step, the Exp.-ECAP die was optimized utilizing FEA, artificial neural network (ANN) and genetic algorithms (GA). After obtaining optimum geometry for Exp.-ECAP die, Exp.-ECAP and HECAP processes were completed. At the last step, mechanical tests and microstructural examinations were carried out.

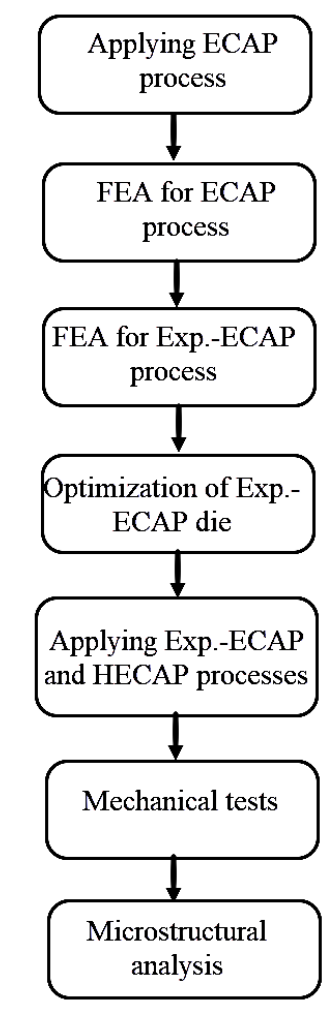

Fig. 1. Flow chart of the methodology applied within the study

The flow chart of the methodology applied within the scope of the study can be seen in Figure 1 . Although the study was carried out in the order shown in the flow chart, experimental and numerical studies of ECAP, Exp.-ECAP and HECAP processes are given under the same titles.

\subsection{Experimental study}

Within the scope of the experimental study, firstly pure copper specimens were prepared for ECAP and Exp.-ECAP processes. The channel diameter in the ECAP die is $20 \mathrm{~mm}$, while the channel diameter in the Exp.-ECAP die is $16 \mathrm{~mm}$. For this reason, the specimens prepared are not the same size. Since it has been shown in the study conducted by Frint et al. that the differences in specimen sizes do not affect the ECAP process [23], it is possible to say that there will be no inconsistency in the comparison of the 
results obtained. The prepared copper specimens were annealed at $600{ }^{\circ} \mathrm{C}$ for 2 hours. ECAP process was carried out after annealing from one pass to four passes. Hexa-ECAP die designed by Kaya was utilized for the ECAP process [24, 25]. The ECAP process was carried out at $200{ }^{\circ} \mathrm{C}$ and the preferred pressing speed is $1 \mathrm{~mm} / \mathrm{s}$. Molybdenum disulfide $\left(\mathrm{MoS}_{2}\right)$ was used as a lubricant in order to minimize the friction between the specimen and the die during the process. During the ECAP processes, load and time graphs were obtained to be used in the verification of finite element analysis. The Hexa-ECAP die and the CAD geometry of the die are shown in Fig. 2 (a) and Fig. 2 (b). Also, ECAPed copper is shown in Fig. 2 (b).

After the ECAP process, the Exp.-ECAP process was carried out from one pass to four passes as well as in the ECAP process. With the preferred operating temperature and pressing speed values for the Exp.-ECAP process, the lubricant is the same as those used in the ECAP process. The CAD geometry of the die and plunger used in the Exp.-ECAP process is shown in Fig. 2 (c), while the die itself and the Exp.-ECAPed specimen are shown in Fig. 2 (d). After the completion of the Exp.-ECAP process, the HECAP process was carried out. The HECAP process has been applied in two stages. First of all, copper specimens were subjected to 1 pass and 4 passes ECAP process. Later, the diameters of the ECAPed specimens were reduced to a diameter compatible with the Exp.-ECAP die. Subsequently, one passage Exp.-ECAP process was applied to ECAPed specimens with 1 pass and 4 passes.

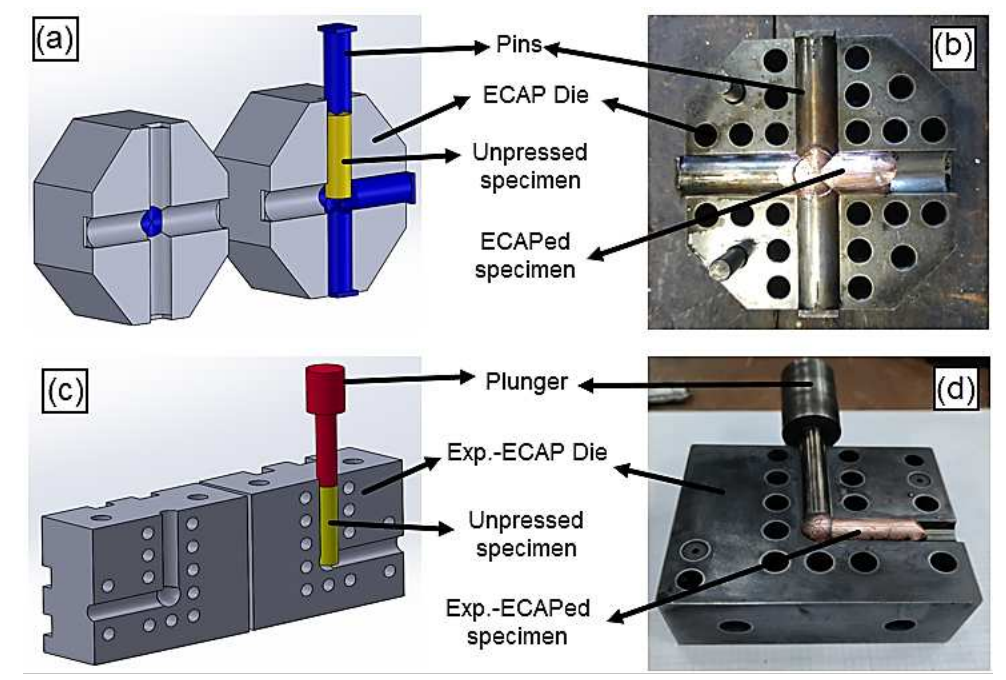

Fig. 2 (a) ECAP die CAD geometry, (b) ECAP die and processed specimen, (c) Exp.- ECAP die CAD geometry, (d) Exp.-ECAPed die and processed specimen

Mechanical tests of processed specimens were carried out after ECAP, Exp.-ECAP and HECAP processes. First of all, tensile test specimens and hardness test specimens were prepared. Secondly, the tensile tests were carried at room temperature and the preferred tension speed is $1 \mathrm{~mm} / \mathrm{s}$. The tensile tests were repeated three times for each pass and the average results were taken as the tensile test result. After the tensile tests were carried out, fracture surfaces were visualized by SEM. Information about the fracture mechanism was obtained by examining the fracture surface on the obtained images. Later, microhardness tests were carried out using the Vickers (HV) method. Hardness values were taken from five different points along the radius on the hardness specimen prepared for all cases. The average of these values was accepted as the hardness value. While the load used during the tests is $50 \mathrm{gf}$, the dwell time is $10 \mathrm{~s}$.

Microstructure studies carried out within the scope of the study consist of four main steps. Before proceeding to these steps, the surfaces of the specimens used in hardness tests were subjected to grinding and polishing for microstructure studies. The copper specimens were then etched for OM imaging using an etchant composed of $1 \mathrm{~g} \mathrm{FeCl}_{3}, 10 \mathrm{ml} \mathrm{HCl}, 100 \mathrm{ml}$ distilled water. Etched specimens were visualized 
by OM. The grain sizes were measured from the OM images obtained by using NIS Element Basic Research software.

\subsection{Finite element analysis}

The simulation procedure of this study consists of two parts. In the first part, a FE model was generated to simulate the ECAP process. For this purpose, Deform 3D software, which is frequently preferred in SPD studies, was preferred. CAD geometries of the die and specimen shown in Figure 1. (a) are used in the FE model. While the die and pins are modeled as rigid, the specimen is modeled as a plastic material. Subsequently, the mesh structure of the specimen was created from 50000 elements. The initially created mesh structure changes during FEA due to its remeshing feature. Thus, high strains occurring in the specimen could be calculated. Boundary conditions such as process temperature and pressing speed in the ECAP process were taken to be the same for FE model. Finally, the friction coefficient between the specimen and the die was taken as 0.08 . This coefficient was determined taking into account the lubricant used. After FE model was created, the simulation part was started and FEA was performed. Then, the load-stroke curves obtained from the experimental and numerical analyses are compared for the validation of FE model.

In the second part, FE model has been generated for the Exp.-ECAP process. While generating the FE model for the Exp.-ECAP process, all the boundary condition used in FE model of the ECAP process. Since the only significant differences between the two processes are the die geometry and dimensions, the FE model generated for the Exp.-ECAP process is assumed as also validated. In the following part of the study, the validity of this assumption has been proven by comparing numerical and experimental studies.

\subsection{Optimization of Exp.-ECAP die}

Optimization of an Exp.-ECAP die was previously done by Fereshteh-Saniee et al [22]. However, in the mentioned study, optimization was done separately for two different objective functions. However, dies were not produced for the optimum geometries obtained and the Exp.-ECAP process was not applied for any specimen. In this study, optimization has been performed by using a final objective function in which two different objective functions are equally effective and a die has been produced for the obtained optimum geometry. In addition, one of the two objective functions used was determined as the maximum load that occurred on the die during the process, unlike the reference optimization study. The Exp.-ECAP process was applied to pure copper specimens by using the optimum die produced at the end of the study. The optimization process carried out in this study consists of four main stages: design of experiments, objective function, artificial neural network and genetic algorithm.

\subsubsection{Design of experiments}

The geometric parameters taken into account in the optimization process are are as shown in Fig. 3. These geometric parameters are the channel diameter $\left(D_{0}\right)$, the diameter of the spherical cavity $\left(D_{1}\right)$, the fillet radius (r), and eccentricity of the cavity center with respect to the intersect of the centerlines of the channels (e). These parameters were nondimensionalized as in the reference study as follow[22]:

$\alpha=\mathrm{R}_{0} / \mathrm{R}_{1}$

$\beta=r / R_{1}$

$\gamma=\mathrm{e} / \mathrm{R}_{1}$ 


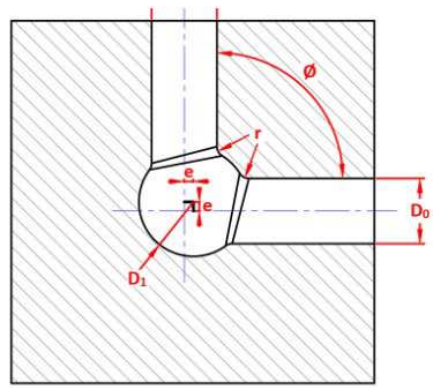

Fig. 3 Geometrical parameters of Exp.-ECAP die

After that, the design of the experiment was carried out by adhering to the limit values obtained for dimensionless parameters in the reference study [22]. A total of 30 experiments were determined to be simulated using the finite element method and were shown in Table 1.

Table 1.Design of experiments for FE analysis

\begin{tabular}{|c|c|c|c|c|c|c|c|c|c|c|c|}
\hline $\begin{array}{c}\text { Analysis } \\
\text { No }\end{array}$ & $\alpha$ & $\beta$ & $\gamma$ & $\begin{array}{c}\text { Analysis } \\
\text { No }\end{array}$ & $\alpha$ & $\beta$ & $\gamma$ & $\begin{array}{c}\text { Analysis } \\
\text { No }\end{array}$ & $\alpha$ & $\beta$ & $\gamma$ \\
\hline 1 & 0.45 & 0.05 & 0.05 & 11 & 0.6 & 0.15 & 0.1 & 21 & 0.65 & 0.1 & 0.05 \\
\hline 2 & 0.5 & 0.15 & 0.1 & 12 & 0.6 & 0.1 & 0.1 & 22 & 0.65 & 0.1 & 0.1 \\
\hline 3 & 0.5 & 0.1 & 0.1 & 13 & 0.6 & 0.05 & 0.1 & 23 & 0.65 & 0.15 & 0.1 \\
\hline 4 & 0.5 & 0.05 & 0.1 & 14 & 0.6 & 0.15 & 0.05 & 24 & 0.7 & 0.1 & 0.1 \\
\hline 5 & 0.5 & 0.15 & 0.05 & 15 & 0.6 & 0.1 & 0.05 & 25 & 0.7 & 0.05 & 0.1 \\
\hline 6 & 0.5 & 0.1 & 0.05 & 16 & 0.6 & 0.05 & 0.05 & 26 & 0.7 & 0.075 & 0.075 \\
\hline 7 & 0.5 & 0.05 & 0.05 & 17 & 0.6 & 0.1 & 0 & 27 & 0.7 & 0.05 & 0.075 \\
\hline 8 & 0.5 & 0.15 & 0 & 18 & 0.6 & 0.05 & 0 & 28 & 0.7 & 0.05 & 0.05 \\
\hline 9 & 0.5 & 0.1 & 0 & 19 & 0.65 & 0.05 & 0 & 29 & 0.75 & 0.05 & 0.1 \\
\hline 10 & 0.5 & 0.05 & 0 & 20 & 0.65 & 0.05 & 0.05 & 30 & 0.8071 & 0 & 0.1 \\
\hline
\end{tabular}

\subsubsection{Objective functions}

As stated before, the optimization process is carried out for two different objective functions. Optimization is carried out by creating a final objective function in which two different objective functions are equally effective.

There are studies showing that there is a relationship between the changes in the mechanical properties of the specimen in excessive plastic deformation applications and the effective plastic strain in the specimen during the process[26]. In specimens subjected to the SPD process, homogeneity is important as well as the magnitude of the strain values. It is seen that more homogeneous hardness values are obtained with a more homogeneous strain distribution. For this reason, strain homogeneity calculations have been made in SPD studies in recent years[27, 28]. The coefficient of variance (CV) is a statistical formula used to calculate the distribution around the mean of any data set. This formula was used to calculate strain inhomogeneity by Basavaraj et al. and called the coefficient of variance for effective plastic strain $\left(C V \varepsilon_{\mathrm{p}}\right)$ [28]. This formula was chosen as the first objective function to be used in the optimization study.

Objective function $1=\mathrm{CV} \varepsilon_{p}=\operatorname{Stdev} \varepsilon_{p} / A v \varepsilon_{p}$

where $\operatorname{Stdev} \varepsilon_{\mathrm{p}}$ is the standard deviation of effective plastic strain and $A v \varepsilon_{\mathrm{p}}$ is the average of effective plastic strain. Effective plastic strain values were extracted from 50 points from the transverse plane of the Exp.-ECAPed specimen as shown in Fig. 4. 


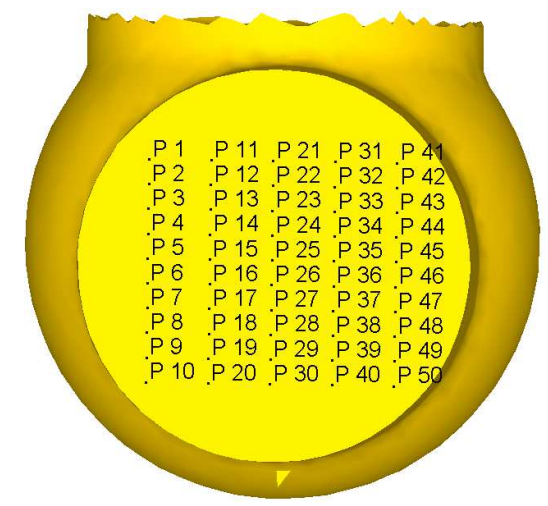

Fig. 4. The pattern of the points used to extract effective strain values

Dies used in ECAP and similar studies are exposed to high loads during the process. In some cases, dies are damaged due to improper design. In order to eliminate this situation, larger sizes are generally preferred in dies, thus both the die costs increase and the application of the process becomes more difficult as a result of the increase in size. Since the increased extrusion rate in the Exp.-ECAP die will increase the resulting load, it would be reasonable to use an objective function that will minimize the load by controlling the extrusion rate. For this reason, the second objective function to be used in the optimization process has been determined as the maximum load (ML) to which the die is exposed.

\section{Objective function $2=M L$}

A final form of objective function in which the two determined objective functions are equally effective is given in equation (4). This objective function is used to obtain the optimum die geometry. Thus, a single optimum geometry could be obtained.

Final objective function $=0.5 *$ Objective function $1+0.5 *$ Objective function 2

Since there are no theoretical or empirical equations that give the values in the first and second objective functions, network files were generated at the next step by using the ANN method to obtain the determined objective functions.

\subsubsection{Artificial neural network}

Artificial neural network (ANN) is a tool preferred to use instead of making hard-to-repeat experiments and time-consuming simulations. It is also a tool used in optimization operations when it is not possible to specify objective functions mathematically. Within the scope of this study, since the objective functions cannot be obtained mathematically, the ANN method was used. The generated network files receive alpha, beta and gamma as input and predict $C V \varepsilon_{p}$ and ML. The network files have a backpropagation algorithm and consist of four layers, namely the input layer, two hidden layers and the output layer. While the preferred training function in the network file was Lavenberg-Marquardt, the number of neurons used in hidden layers was determined as 15 . While deciding on these parameters, many trials have been made and those with the best performance have been chosen. Neural network files were generated using the inputs and outputs of $30 \mathrm{FE}$ analyzes. Since $\mathrm{CV} \varepsilon_{p}$ and ML results obtained from $30 \mathrm{FE}$ analyses have different ranges, before using these data in ANN, they were normalized between 0.1 and 0.9 in order to make them have equal effect on the final objective function. Data of 20 of these analyzes were used for training, while 10 of them were used for testing.

After the network files generated for $\mathrm{CV} \varepsilon_{p}$ and $\mathrm{ML}$ were put into the final objective function, the optimization process was carried out using the genetic algorithm. 


\section{Results and Discussion}

The results obtained within the scope of the study are given under four main titles. First, the results obtained from the FE analysis of the ECAP process are given. Secondly, optimization results are given. FE analysis results of the Exp.-ECAP process are also given with the optimization results. Subsequently, the mechanical properties of the specimens subjected to ECAP, Exp.-ECAP and HECAP processes were given. Finally, the microstructure results of these specimens are given.

\subsection{Results for finite element analysis of ECAP process}

ECAPed specimen shapes obtained from experiment and FE analysis are compared in Fig. 5 (a) and (b). In addition, the curves showing the load applied to the die during the ECAP process and stroke values were obtained both experimentally and numerically and shown in Fig. 5 (c). Considering results given in Fig. 5 (a) - (c), it can be concluded that the FE analysis performed for the ECAP process is validated. The effective strain distribution of the ECAPed specimen is shown in Fig. 5 (d). The average strain value of the specimen was obtained by taking the average of the values extracted from 50 points on the transverse section. Also, the $\mathrm{CV} \varepsilon_{p}$ given in equation (2) is also calculated by taking the values extracted from these 50 points. The average strain value obtained is 1.25 and this value is very close to 1.15 which is the theoretical value that should be in the ECAP process. $\mathrm{CV} \varepsilon_{p}$ value was also calculated as 0.434 .

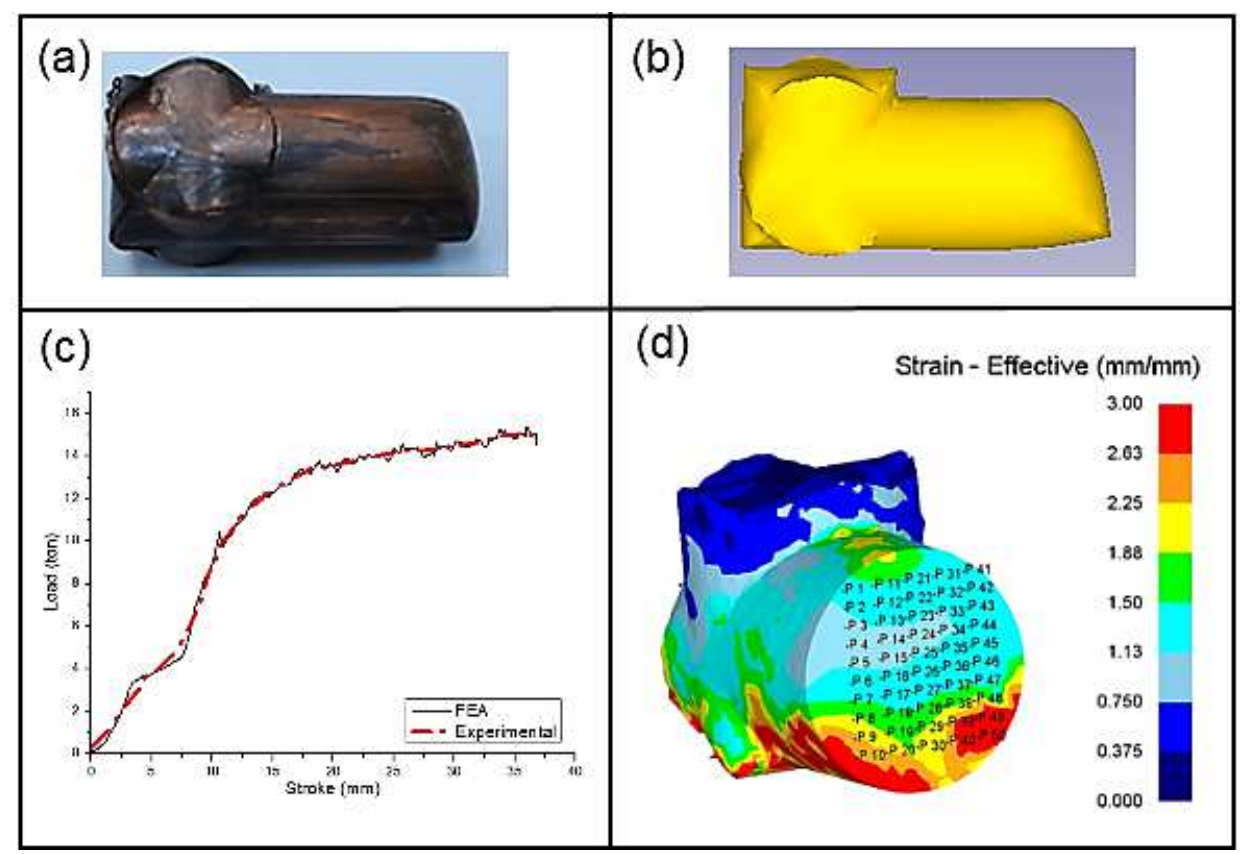

Fig. 5. (a) ECAPed specimen in the experiment, (b) ECAPed in FE analysis, (c) Load-stroke curves for ECAP process, (d) Numerical results for ECAP process

\subsection{Results of optimization}

The performances of the ANN files used in the optimization process and used to calculate $\mathrm{CV} \varepsilon_{p}$ and ML for any parameter set $(\alpha, \beta$ and $\gamma)$ are given in Fig. 6 and Table 2. Training and testing performance of maximum load (ML) neural network can be seen in Fig. 6 (a) and (b). Correlation coefficients of training and test data sets for ML neural network are given in Table 2 as 1 and 0.999 , respectively. These correlation coefficient values are quite satisfactory. Also, the average absolute error values calculated for training and test data of ML neural network are $3.37 \mathrm{e}-09 \%$ and $0.177 \%$. On the other hand, Fig. 6 (c) and (d) are displaying the performance of training and test data for the coefficient of variance for plastic strain $\left(\mathrm{CV} \varepsilon_{p}\right)$ neural network. Calculated correlation coefficients for training and test data are given in Table 2 as 0.999 and 0.890 . Although the correlation coefficient value of the test data of $\mathrm{CV} \varepsilon_{p}$ is lower than that of ML, it is at an acceptably good level. Finally, the average absolute error values calculated for training and test data of $\mathrm{CV} \varepsilon_{p}$ neural network are $0.022 \%$ and $2.655 \%$. 


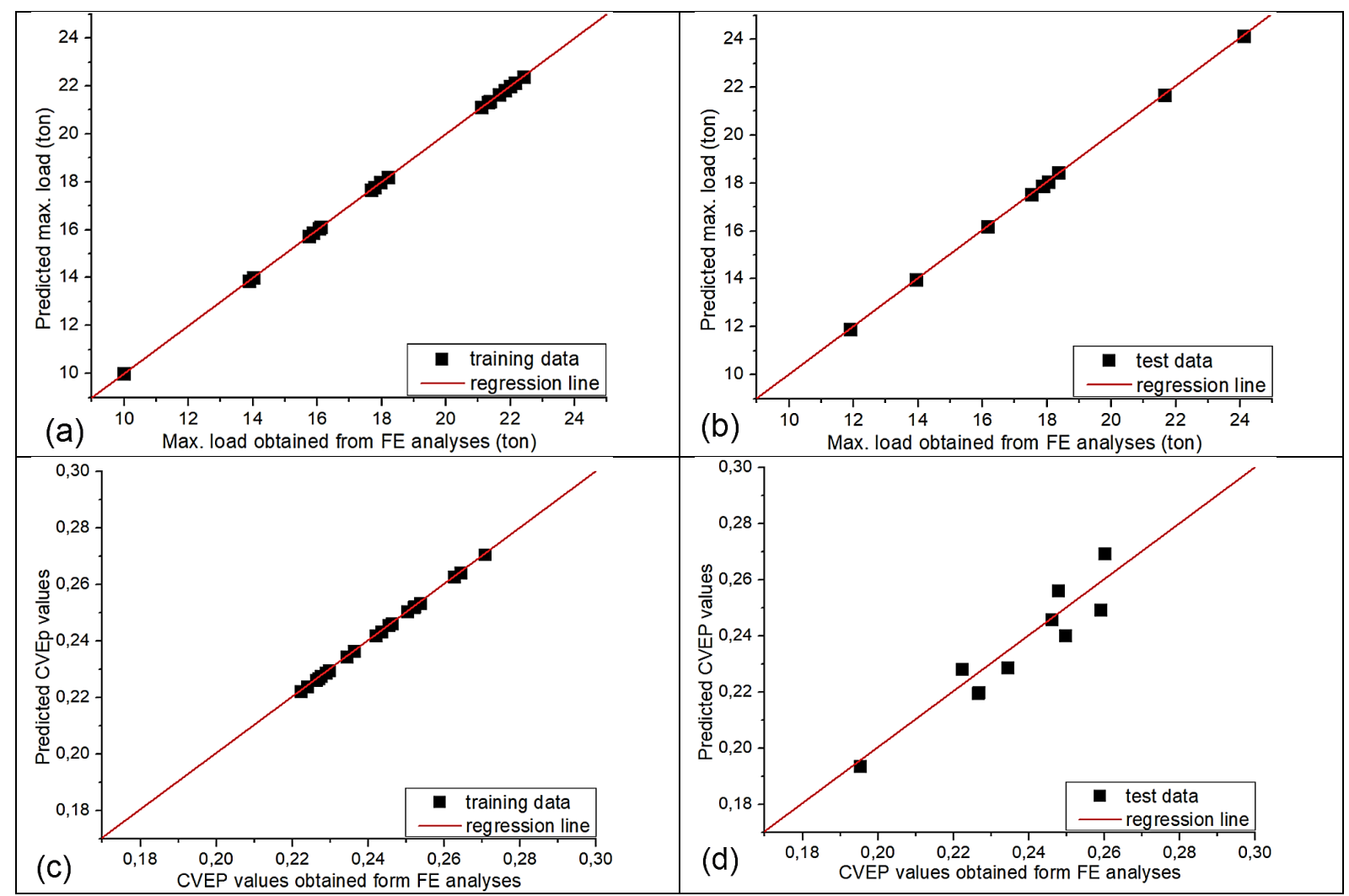

Fig. 6 Predicted values vs FE analysis values for (a) training data of ML (maximum load) neural network, (b) test data of ML neural network, (c) training data of $\mathrm{CV} \varepsilon_{p}$ (coefficient of variance for plastic strain) neural network, (b) test data of $\mathrm{CV} \varepsilon_{p}$ neural network

Table 2. Results for the performance of $\mathrm{ML}$ and $\mathrm{CV} \varepsilon_{p}$ neural networks

\begin{tabular}{|c|c|c|c|c|}
\hline & \multicolumn{2}{|c|}{ Maximum Load (ML) } & \multicolumn{2}{c|}{$\begin{array}{c}\text { Coefficient of Variance for Plastic } \\
\text { Strain }\left(\mathrm{CV} \varepsilon_{p}\right)\end{array}$} \\
\hline & Training data & Test data & Training data & Test data \\
\hline Average absolute error (\%) & $3.37 \mathrm{e}-09$ & 0.177 & 0.022 & 2.655 \\
\hline Maximum absolute error (\%) & $1.15 \mathrm{e}-08$ & 0.423 & 0.107 & 3.811 \\
\hline Correlation coefficient ( $\left.{ }^{2}\right)$ & 1 & 0.999 & 0.999 & 0.890 \\
\hline
\end{tabular}

The values obtained for the nondimensional $\alpha, \beta$ and $\gamma$ parameters as a result of the optimization and the values obtained for the D1, $\mathrm{r}$ and e parameters in return for these values, together with the $\mathrm{CV} \varepsilon_{p}$ and ML values expected to be obtained as a result of the optimum design are given in Table 3.

Table 3. Optimum parameters obtained for Exp.-ECAP die

\begin{tabular}{|c|c|c|c|c|c|c|c|}
\hline$\alpha$ & $\beta$ & $\gamma$ & $\mathrm{D}_{1}(\mathrm{~mm})$ & $\mathrm{r}(\mathrm{mm})$ & $\mathrm{e}(\mathrm{mm})$ & $\mathrm{CV} \varepsilon_{p}$ & ML (ton) \\
\hline 0.766 & 0.021 & 0.086 & 20.886 & 0.222 & 0.891 & 0.232 & 11.5 \\
\hline
\end{tabular}

When the results are examined, it is seen that the $\alpha$ is 0.766 , which is a value close to the upper limit. This shows that the $\alpha$, also expressed as inverse extrusion rate, is more effective on ML than $\mathrm{CV} \varepsilon_{p}$. In addition, the ML value constantly decreases with the decrease of the extrusion rate. On the other hand, 
although the $\mathrm{CV} \varepsilon_{p}$ decreases with the increase of the extrusion rate, this situation changes after a certain value. The biggest reason for this is that the increasing extrusion rate is not reflected in the strain value as it should be in the theoretical equation which is shown in Eqn (5). This has been explained in detail by Fereshteh-Saniee et al [22]. After a certain extrusion ratio, some part of the specimen remains constant in the spherical cavity and the extrusion rate takes a smaller value than it is. Thus, the average strain value does not increase and the $\mathrm{CV} \varepsilon_{p}$ cannot sustain its decrease. A similar situation can be seen in this study. Fig. 7 is comparing the total velocity distribution across the spherical cavity for different extrusion ratios.

The velocity values in the spherical cavity part are very close to the channel part for the lowest extrusion ratio $(\alpha=0.8071)$ in Fig.7 (a). However, the total velocity of the circled area is close to zero for the highest extrusion ratio $(\alpha=0.45)$ as shown in Fig 7 (b). The circled area is nearly motionless and acts as a wall. This situation leads to a decrease in strain gained from the first term of Eqn (5).

$$
\varepsilon=4 \ln \frac{\mathrm{D}_{1}}{\mathrm{D}_{0}}+\left[\frac{2 \cot \left(\frac{\emptyset}{2}+\frac{\Psi}{2}\right)+\Psi \operatorname{cosec}\left(\frac{\emptyset}{2}+\frac{\Psi}{2}\right)}{\sqrt{3}}\right]
$$

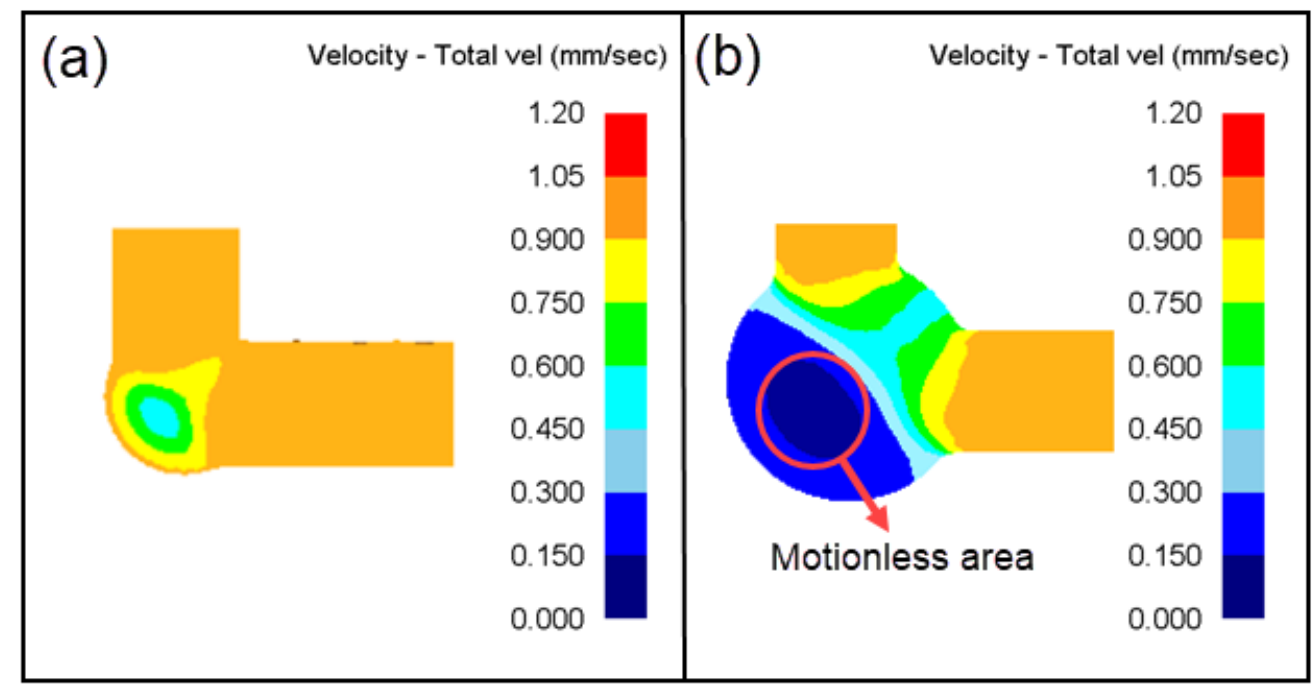

Fig. 7. Total velocity distribution across the spherical cavity for (a) $\alpha=0.8071$ and (b) $\alpha=0.45$

After the optimum die geometry was manufactured, the experimental and numerical images of the specimen pressed in this die were compared in Fig. 8 (a) and (b). In addition, the load-stroke curves of the Exp.-ECAP process carried out in the optimum die were obtained experimentally and numerically and compared in Fig. 8 (c). As a result of these comparisons, the earlier assumption made that the Exp.ECAP finite element analysis was validated was proven. It is also seen that the maximum load (ML) values for both curves in the graph are very close to the ML value in Table 3. Optimum parameters obtained for Exp.-ECAP die While the maximum load value (ML) obtained as a result of the optimization is 11.5 tons, the experimental maximum load during the ECAP process carried out in the produced optimum die is 11.4 tons and the maximum load in the FE analysis for the optimum die is 11.65 tons. On the other hand, the $\mathrm{CV} \varepsilon_{p}$ value calculated for the strain values shown in Fig. 8 (d) obtained from the FE analysis performed for the optimum die is 0.245 . This value, is very close to 0.232 which is obtained as a result of optimization. These results confirm the validity of the finite element model produced for the Exp.-ECAP process and indicate that the neural networks (ML and $\mathrm{CV} \varepsilon_{p}$ ) have sufficient performance to predict the maximum load and coefficient of variance for effective plastic strain. In addition, the $\mathrm{CV} \varepsilon_{p}$ value obtained from the FE analysis for the optimum Exp.-ECAP die and the $\mathrm{CV} \varepsilon_{p}$ 
value obtained from the FE analysis for the ECAP process are 0.434 and 0.245 , respectively. This shows that the strain distribution of the specimen as a result of the Exp.-ECAP process is more homogeneous.

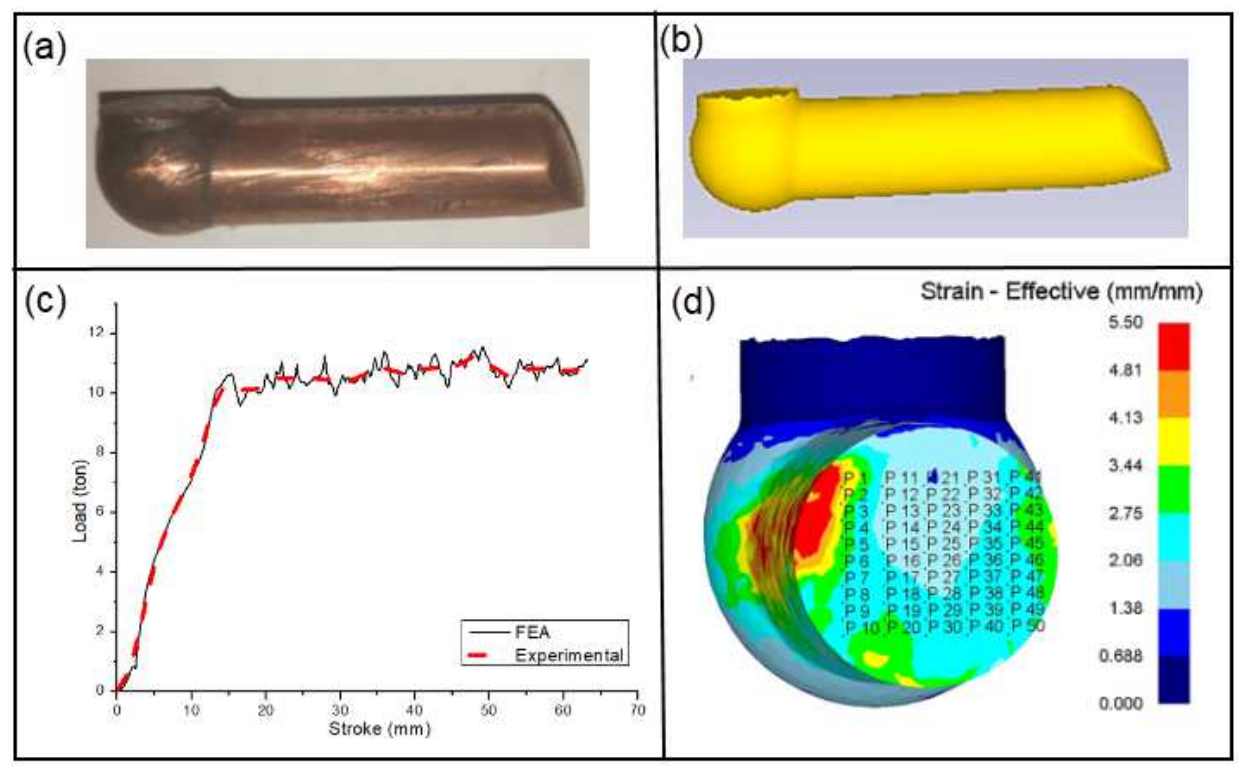

Fig. 8. (a) Exp.-ECAPed specimen in experiment, (b) Exp.-ECAPed specimen in FE analysis, (c) Load- stroke curves for Exp.-ECAP process, (d) Numerical results for Exp.-ECAP process

\subsection{Results for mechanical properties}

In this study, the first of the mechanical tests applied to processed specimens is the tensile test. Fig. 9 (a) shows a tensile test specimen produced in accordance with the ASTM-E8 standard, and Fig. 9 (c) shows the dimensions of this specimen. Fig. 9 (b) shows a specimen subjected to the tensile test. Tensile tests were carried out in 3 repetitions for each pass of ECAP, Exp.-ECAP and HECAP processes. The stress-strain curves obtained by averaging the three tests performed for each pass are shown in Fig. 10. Also, the yield strength and tensile strength values of each pass of each SPD method are given in Table 4.

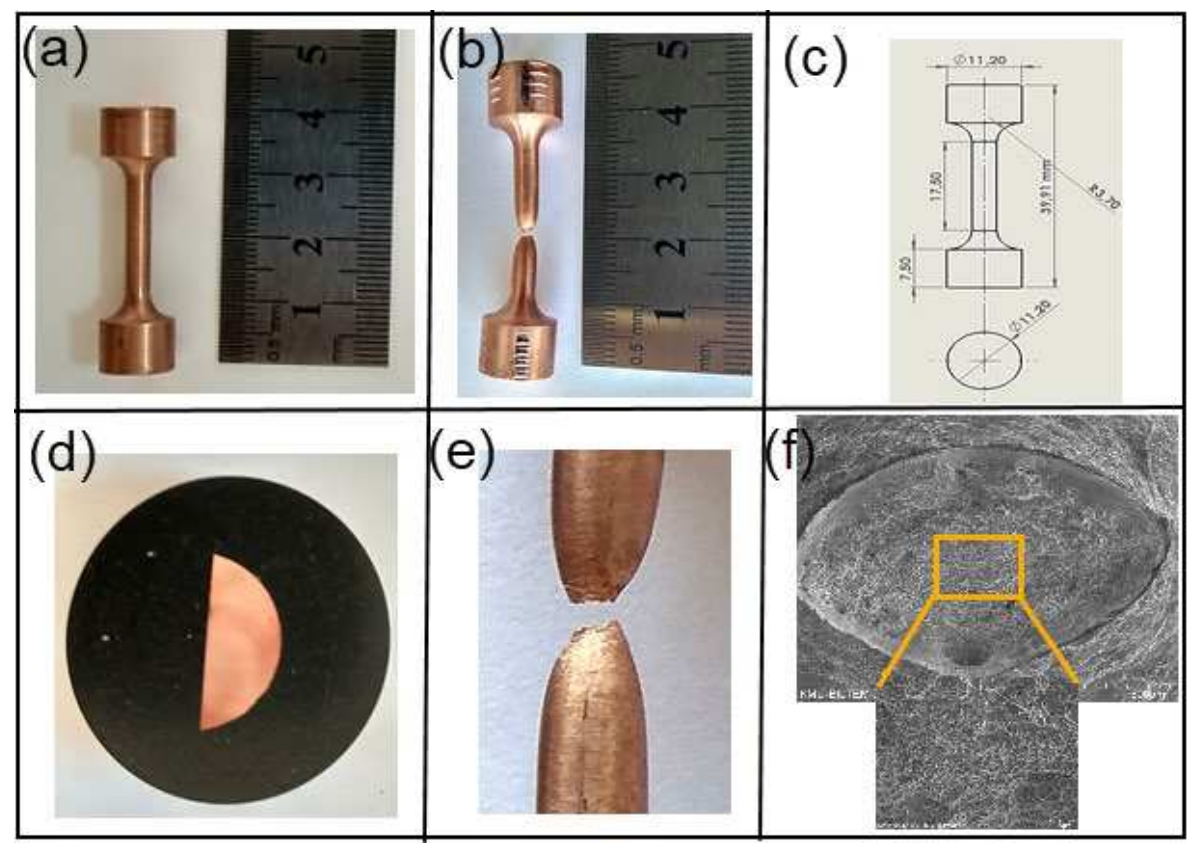

Fig. 9 (a)Tensile test specimen, (b) fractured specimen after tensile test, (c) tensile test specimen dimensions, (d) microstructure analysis and hardness test specimen, (e) fractured specimen (f) fracture surface and fractography 
When the values are examined, it is seen that the yield strength and ultimate tensile strength values increase in both ECAP and Exp.-ECAP processes with the increasing number of passes. Especially, while the strength increases in the first passes were dramatic, elongation values decreased up to $50 \%$ in the first passes. It is seen in Table 4 that the toughness values are lower than the values of the annealed copper specimen, despite the increase in the strength values with the increasing number of passes and the improvement in the elongation values in the progressive passes. When the effects of ECAP and Exp.-ECAP processes on the strength values are compared, it is seen that Exp.-ECAP specimens have higher yield and tensile strength than ECAPed specimens at the same number of passes. This can be attributed to the fact that the specimen is subjected to more strain than the ECAP specimen in the Exp.-ECAP process. In the HECAP process, it was observed that the yield and tensile strength values continued to increase with the Exp.-ECAP process applied to the specimens subjected to the ECAP process. Especially, the strength values of 4 pass Exp.-ECAPed specimens are higher than 4 passes ECAPed +1 pass Exp.-ECAPed specimen shows that the Exp.-ECAP process is more efficient than the ECAP process.
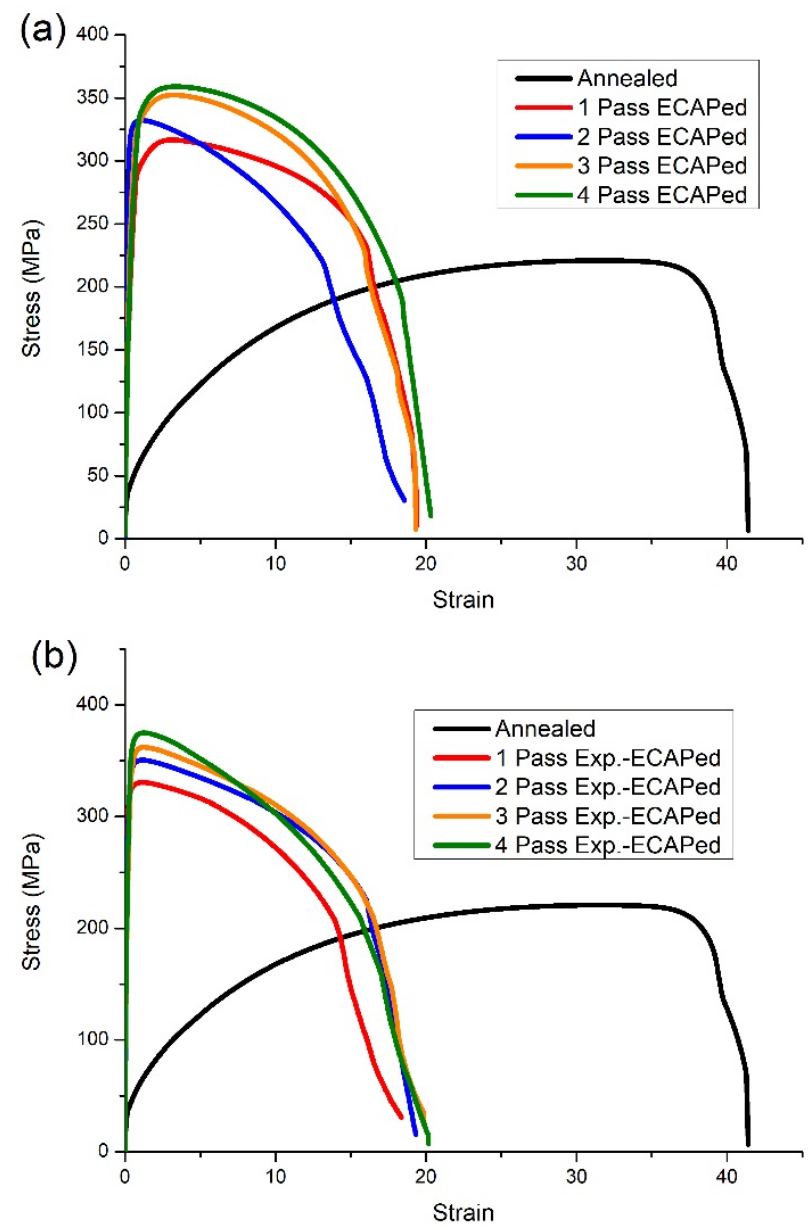


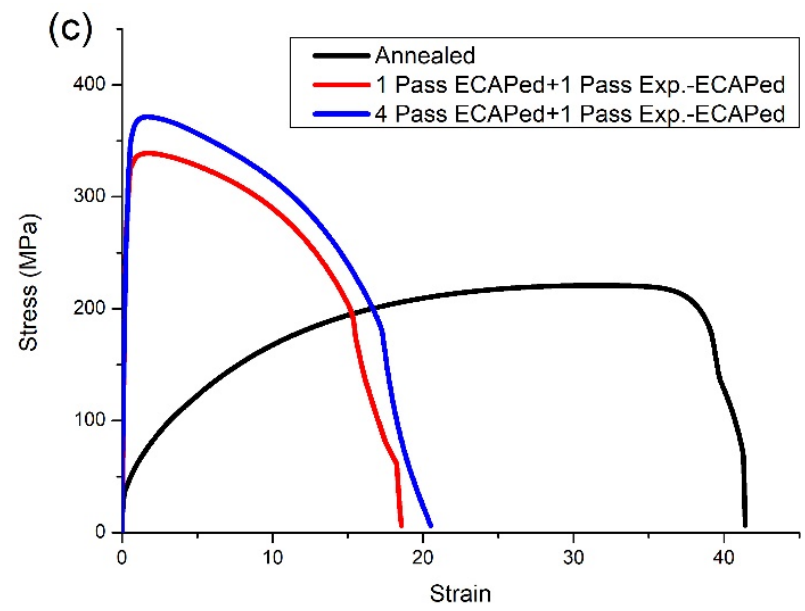

Fig. 10. Stress-strain curves of (a) ECAPed, (b) Exp.-ECAPed and (c) Hybrid ECAPed specimens

After the tensile tests were completed, fracture surface investigation was carried out for these specimens. In Figure 9 (e), the area where the fracture surface examination of a specimen was performed is shown closely. Figure 9 (f) is an example showing where and how the fracture surface images were taken. Fracture surface images taken from all specimens are given in Figure 11. When the broken surfaces are examined, it is seen that the annealed specimen contains quite a lot of dimples and these dimples are larger. It is seen that specimens subjected to ECAP, Exp.-ECAP and HECAP processes contain relatively less dimple and have a less ductile structure. The elongation values obtained from the tensile tests and the images obtained from the fractured surfaces are in consistence.
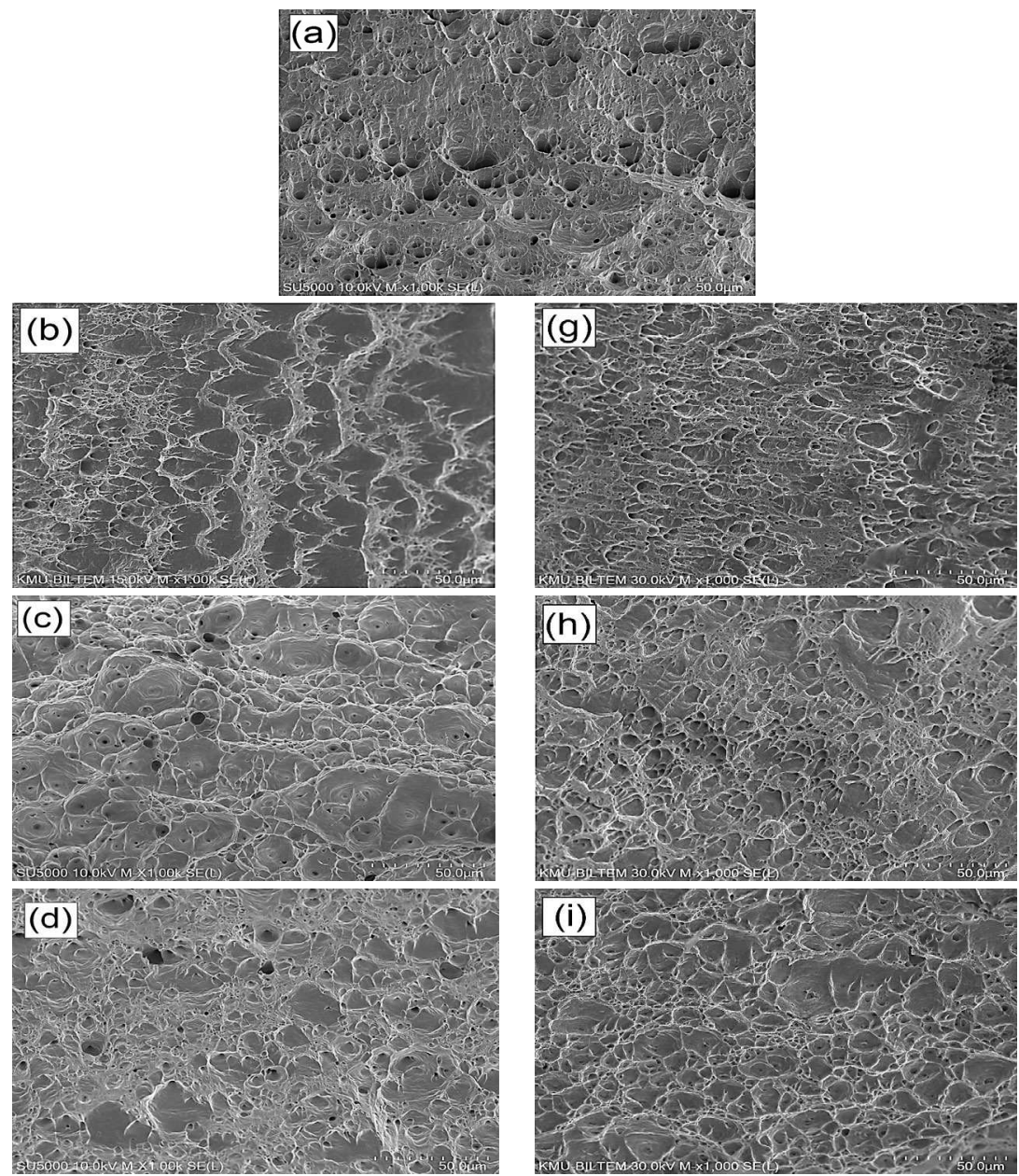

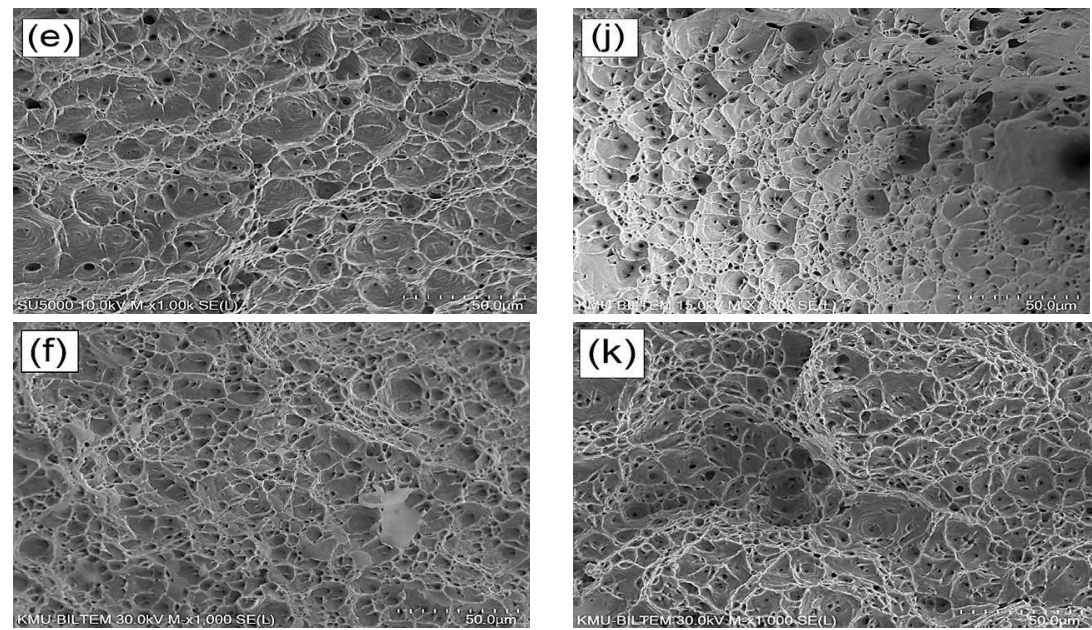

Fig. 11. 1000X Fractography images of (a) annealed, (b)-(e) 1-4 Pass ECAPed, (f)-(i) 1-4 Pass Exp.ECAPed, (j)1 Pass ECAPed+1 Pass Exp.-ECAPed and (k) 4 Pass ECAPed +1 Pass Exp.-ECAPed pure copper specimens

The average hardness values obtained from the hardness measurements are as in Table 4 . When the hardness values were examined, it was seen that the hardness values increased by $65 \%$ and $79 \%$, respectively, with the first passes of the ECAP and Exp.-ECAP processes. With the increasing number of passes in both processes, the hardness values increase, but the rate of increase decreases. When the two processes are compared, it is seen that Exp.-ECAP causes more increase in hardness values compared to ECAP. It is seen that the Exp.-ECAP passes applied after ECAP continues to increase the hardness values.

Table 4.Mechanical properties of annealed, ECAPed 1-4 passes, Exp.-ECAPed 1-4 passes and HECAP processed pure coppers

\begin{tabular}{|l|c|c|c|c|c|}
\hline & $\begin{array}{c}\text { Yield } \\
\text { Strength } \\
(\mathrm{MPa})\end{array}$ & $\begin{array}{c}\text { Ultimate } \\
\text { Tensile } \\
\text { Strength } \\
(\mathrm{MPa})\end{array}$ & $\begin{array}{c}\text { Elongation } \\
\text { at break } \\
(\%)\end{array}$ & $\begin{array}{c}\text { Toughness } \\
\left(\mathrm{MJ} / \mathrm{m}^{3}\right)\end{array}$ & $\begin{array}{c}\text { Hardness } \\
(\mathrm{HV})\end{array}$ \\
\hline Annealed & 48.4 & 220.8 & 41.4 & 74.9 & 65.6 \\
\hline 1 pass ECAPed & 287.6 & 317.0 & 19.4 & 51.4 & 108.8 \\
\hline 2 pass ECAPed & 299.5 & 332.3 & 18.6 & 45.0 & 120.3 \\
\hline 3 pass ECAPed & 318.5 & 353.0 & 19.3 & 55.1 & 126.7 \\
\hline 4 pass ECAPed & 332.1 & 359.2 & 20.3 & 59.5 & 127.3 \\
\hline 1 pass Exp.-ECAPed & 301.9 & 330.3 & 18.4 & 45.1 & 117.5 \\
\hline 2 pass Exp.-ECAPed & 324.2 & 351.0 & 19.3 & 53.4 & 123.9 \\
\hline 3 pass Exp.-ECAPed & 329.8 & 362.0 & 19.9 & 55.1 & 127.8 \\
\hline 4 pass Exp.-ECAPed & 345.5 & 375.0 & 20.2 & 54.0 & 130.4 \\
\hline $\begin{array}{l}\text { 1 Pass ECAPed+ } \\
\text { 1 Pass Exp.-ECAPed }\end{array}$ & 315.5 & 339.8 & 18.5 & 48.4 & 122.4 \\
\hline $\begin{array}{l}\text { 4 Pass ECAPed+ } \\
\text { 1 Pass Exp.-ECAPed }\end{array}$ & 340.3 & 371.8 & 20.5 & 55.8 & 130.1 \\
\hline
\end{tabular}

In recent studies, the distribution of hardness values is also examined, as well as the average hardness values [29]. In addition to having high average hardness values, it is also very important to have a homogeneous distribution. For this reason, the hardness distributions of the specimens were also 
examined in this study. The coefficient of variance (CV) factor used to examine the strain inhomogeneity is adapted as in Eqn. (6) to examine the hardness inhomogeneity:

$$
C V H V=S t d e v H V / A v H V
$$

where StdevHV is the standard deviation of hardness values and AvHV is the average of hardness values. The values obtained using Equation (6) are shown in Fig. 12.

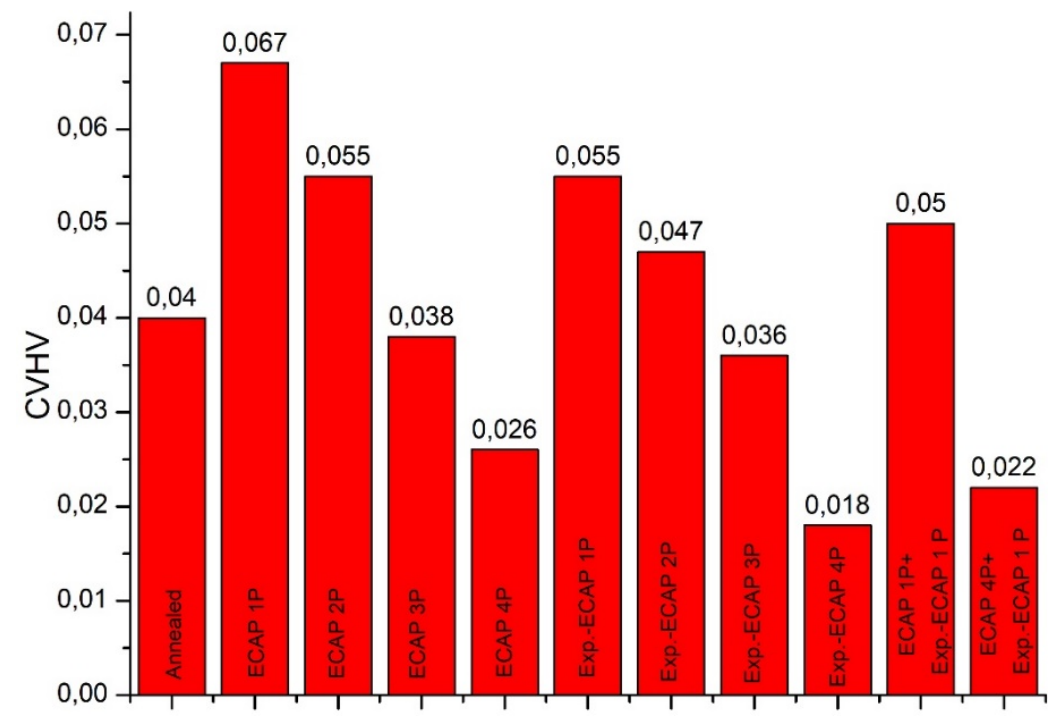

Fig. 12.Coefficient of variance for hardness (CVHV) values of all specimens

When the values are examined, it is seen that CVHV values decrease with the increasing number of passes in ECAP and Exp.-ECAP processes, in other words, the hardness distribution becomes more homogeneous. In addition, it is seen that the Exp.-ECAP process provides a more homogeneous hardness distribution compared to the ECAP process at the same number of passes. This can be attributed to the fact that the optimized Exp.-ECAP die provides a more homogeneous strain distribution during the process than the ECAP die.

\subsection{Results for microstructural analysis}

Fig. 13 shows optical microscope (OM) and scanning electron microscope (SEM) images of specimens subjected to ECAP, Exp.-ECAP and HECAP processes. When OM and SEM images are examined, it is seen that particle sizes decrease with the increase in the number of passes applied in ECAP and Exp.ECAP processes. Also, with the increasing number of passes, orientation is observed in the grains and these orientations are shown with arrows on the OM images. When the average grain sizes given in Table 5 are examined, it is seen that the Exp.-ECAP process reduces the grain sizes more than the ECAP process in the same number of passes. It can be understood from the values in Table 5that the Exp.ECAP passes applied after ECAP within the scope of the HECAP process continue to reduce the grain sizes. In addition to the average particle sizes, the standard error (SE) values calculated using the data obtained from the particle size measurements are also shown in Table 5. SE values were calculated for each specimen to give an idea about the grain size distributions of the microstructure. When SE values are examined, it is seen that ECAP and Exp.-ECAP processes provide a more homogeneous grain distribution with the increasing number of passes. The Exp.-ECAP process enabled the formation of a more homogeneous microstructure compared to the ECAP process. As a result, it can be said that the findings related to grain sizes and distributions are in parallel with the results obtained from hardness and tensile tests. 

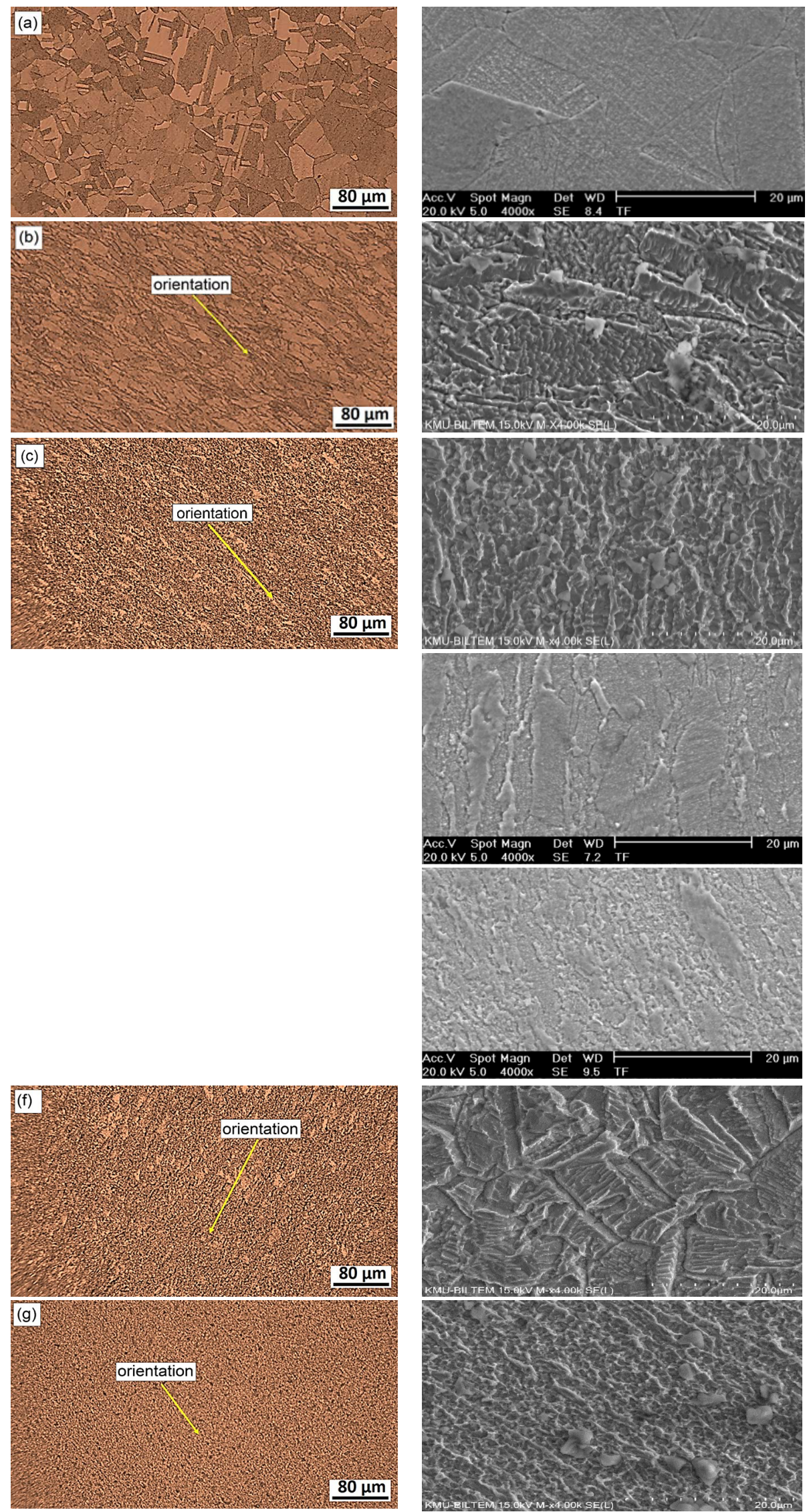

Fig. 13. 200X Optical microscope images (left) and SEM images (right) of (a) annealed, (b) 1 Pass ECAPed, (c) 4 Pass ECAPed, (d) 1 Pass Exp.-ECAPed, (e) 4 Pass Exp.-ECAPed (f) 1 Pass ECAPed +1 Pass Exp.-ECAPed and (g) 4 Pass ECAPed+1 Pass Exp.-ECAPed pure copper specimens 
TEM images and SAED patterns of 4 pass ECAPed, 4 pass Exp.-ECAPed and 4 pass ECAPed +1 pass Exp.-ECAPed specimens are shown in Figure 14. When the TEM images are examined, it is seen that the crystal sizes of 4 pass Exp.-ECAPed and 4 pass ECAPed +1 pass Exp.-ECAPed specimens are smaller than the 4 pass ECAPed specimens. Besides, when the SAED patterns are examined, it is seen that the electron scattering is the highest in the 4 pass Exp.-ECAPed specimen, while the scattering in the 4 pass ECAPed specimen is less than the other two specimens. Using the relationship between the electron scattering and misorientation [30] it is possible to say that, between these three specimens, the specimen with the highest misorientation is the 4 pass Exp.-ECAPed specimen, while the specimen with the lowest misorientation is the 4 pass ECAPed specimen.
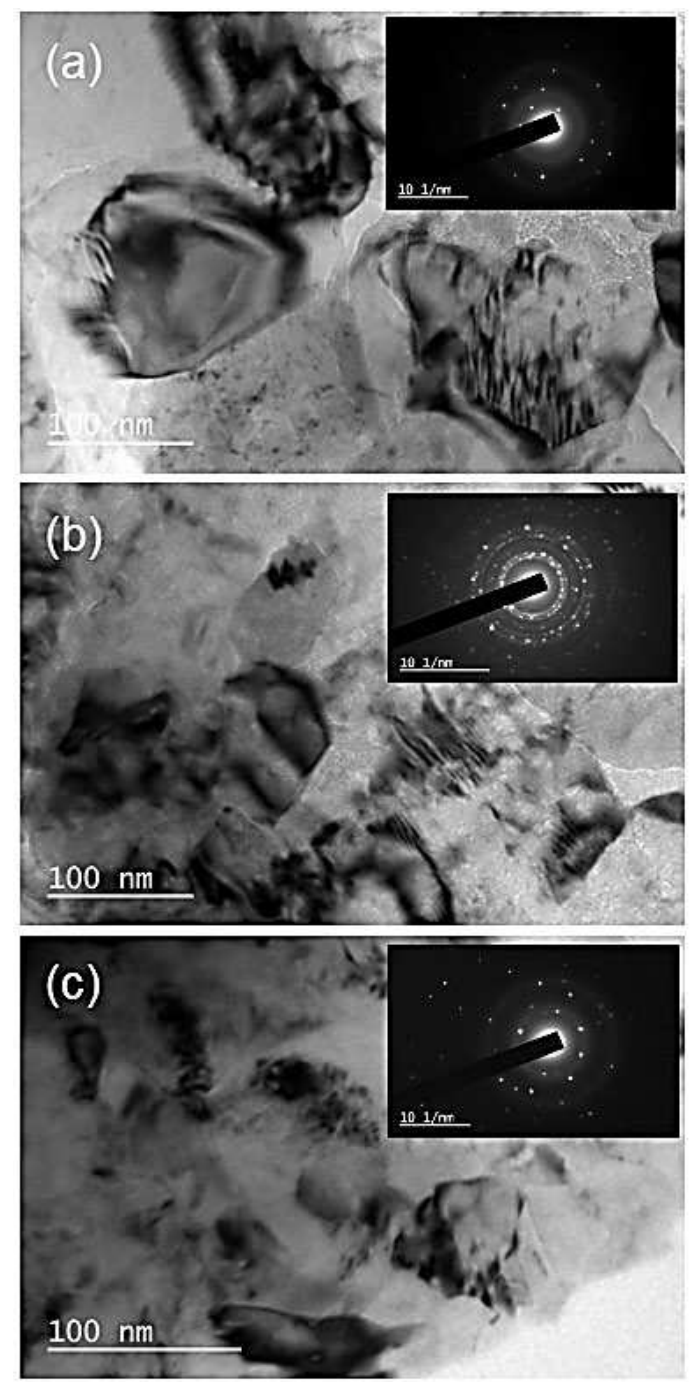

Fig. 14 TEM images and SAED pattern of (a) 4 Pass ECAPed, (b) 4 Pass Exp.-ECAPed and (c) 4 Pass ECAPed+1 Pass Exp.-ECAPed pure copper specimens

The XRD patterns obtained from the XRD study are shown in Figure 15. The crystal size calculation was made for each specimen using the Scherrer and Wilson method [31] on the XRD graphs obtained, and the crystal sizes are given in Table 5. During the calculations, each peak in the XRD graphs was calculated and the average of the obtained crystal sizes was taken as the crystal size for the corresponding specimen. When the results are examined, it is observed that the crystal size values obtained in the first passes in ECAP and Exp.-ECAP processes are quite low compared to the annealed specimen. Also, the decrease in crystal sizes continued with the increasing number of passes. It is observed that the Exp.ECAP passes applied after ECAP within the scope of the HECAP process continue to decrease in 
crystal sizes. When compared, it is also seen that the Exp.-ECAP process causes a greater reduction in crystal size than the ECAP process. The specimen with the smallest crystal size is the 4 pass Exp.ECAPed specimen with $30.8 \mathrm{~nm}$, while the 4 pass ECAPed +1 pass Exp.-ECAPed specimen is the second specimen with $31.2 \mathrm{~nm}$.
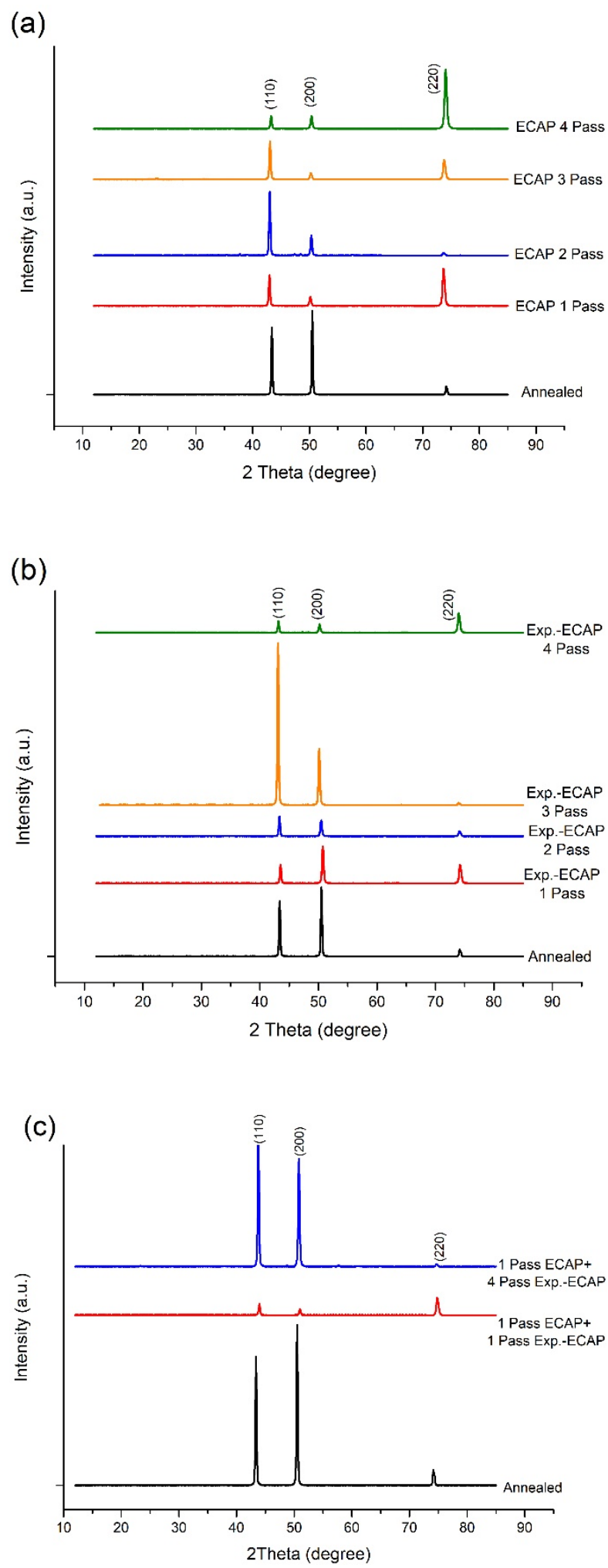

Fig. 15. XRD patterns of pure copper specimens 
The dislocation density of the specimens was calculated with the Williamson-Smallman formula and shown in Table 5. The opposite of the effects of the ECAP and Exp.-ECAP processes on the crystal size is true for the dislocation density, as there is an inverse proportion between the dislocation density and the crystal size according to this formula. Therefore, the 4 pass Exp.-ECAPed and the 4 pass ECAPed +1 pass Exp.-ECAPed specimens with the smallest crystal size have the highest dislocation density.

Table 5.Grain size and crystallite size of pure copper specimens

\begin{tabular}{|l|c|c|c|}
\hline & $\begin{array}{c}\text { Grain size } \\
(\mu \mathrm{m})\end{array}$ & $\begin{array}{c}\text { Crystallite size } \\
(\mathrm{nm})\end{array}$ & $\begin{array}{c}\text { Dislocation density } \mathrm{x} 10^{5} \\
\left(\mathrm{~nm}^{-2}\right)\end{array}$ \\
\hline Annealed & $29.4 \pm 0.194$ & 49.5 & 40.8 \\
\hline 1 pass ECAPed & $13.5 \pm 0.116$ & 35.4 & 79.8 \\
\hline 2 pass ECAPed & $8.8 \pm 0.094$ & 34.2 & 85.5 \\
\hline 3 pass ECAPed & $4.9 \pm 0.066$ & 33.1 & 91.3 \\
\hline 4 pass ECAPed & $3.4 \pm 0.068$ & 31.5 & 100.8 \\
\hline 1 pass Exp.-ECAPed & $12.0 \pm 0.109$ & 34.6 & 83.5 \\
\hline 2 pass Exp.-ECAPed & $7.2 \pm 0.090$ & 33.5 & 89.1 \\
\hline 3 pass Exp.-ECAPed & $4.0 \pm 0.070$ & 32.1 & 97.0 \\
\hline 4 pass Exp.-ECAPed & $2.3 \pm 0.055$ & 30.8 & 105.4 \\
\hline $\begin{array}{l}\text { 1 Pass ECAPed+ } \\
\text { 1 Pass Exp.-ECAPed }\end{array}$ & $7.4 \pm 0.091$ & 33.9 & 87.0 \\
\hline $\begin{array}{l}\text { 4 Pass ECAPed+ } \\
\text { 1 Pass Exp.-ECAPed }\end{array}$ & $2.5 \pm 0.062$ & 31.2 & 102.7 \\
\hline
\end{tabular}

\section{Conclusions}

In this study, ECAP, Exp.-ECAP and HECAP processes were applied to pure copper specimens. The die used in Exp.-ECAP and HECAP processes has been optimized in a way that $\mathrm{CV} \varepsilon_{p}$ and maximum load objective functions are equally effective. The effects of these three processes on the mechanical properties and microstructures of the specimens were investigated. Also, the strain formed during the process in the specimens and the homogeneity of the hardness values obtained as a result of the process were examined. The results obtained are as follows:

- $\quad$ Average grain size was decreased by $88.4 \%$ after 4 pass ECAP, while it was decreased by 92.2 $\%$ after 4 pass Exp.-ECAP. The reduction in average grain size as a result of 4 pass ECAP +1 pass Exp.ECAP is $91.4 \%$.

- $\quad$ SE values obtained for 4 pass ECAPed, 4 pass Exp.-ECAPed and 4 pass ECAPed 1 Pass Exp.ECAPed specimens are $0.068 \mu \mathrm{m}, 0.055 \mu \mathrm{m}$ and $0.062 \mu \mathrm{m}$, respectively.

- $\quad$ The lowest crystallite size and the highest dislocation density were achieved as a result of 4 pass Exp.-ECAP.

- $\quad$ The specimen having the highest UTS is 4 pass Exp.-ECAPed specimen with $375.0 \mathrm{MPa} .1$ pass ECAPed specimen has $317.0 \mathrm{MPa}$ UTS while 1 pass ECAP + 1 pass Exp.-ECAP specimen has 339.8 MPa UTS. Likewise, 4 pass ECAPed specimen has 359.2 MPa UTS while 4 pass ECAP +1 pass Exp.ECAP specimen has $371.8 \mathrm{MPa}$ UTS. From here, it is seen that the Exp.-ECAP passes applied after ECAP within the scope of the HECAP process cause an increase in UTS. It is understood by comparing the UTS values of 1 pass ECAPed (317.0 MPa), 2 pass ECAPed (332.3 MPa) and 1 pass ECAPed + 1 pass Exp.-ECAPed (339.8 MPa) specimens that this increase is higher than the increase obtained as a result of the extra ECAP passes applied after ECAP.

- $\quad$ The annealed specimen has the maximum toughness value of $74.9 \mathrm{MJ} / \mathrm{m}^{3}$. The processed specimen with the highest toughness is 4 pass ECAPed specimen and it has $59.574 .9 \mathrm{MJ} / \mathrm{m}^{3}$. 
- $\quad$ The highest hardness value (130.4 HV) was achieved after the 4 pass Exp.-ECAP process. The hardness of pass ECAPed +1 pass Exp.-ECAPed specimen is $130.1 \mathrm{HV}$ which is close to the highest hardness value (130.4 HV) and greater than the hardness of 4 pass ECAPed specimen (127.3HV).

- $\quad$ The specimen having the lowest CVHV and thus the most homogeneous hardness distribution is 4 pass Exp.-ECAPed specimen (0.018). Exp.-ECAP passes applied after the ECAP process makes the hardness distribution more homogenous. This can be seen comparing CVHV values calculated for 1 pass ECAPed (0.067), 2 pass ECAPed specimen (0.055) and 1 pass ECAPed +1 pass Exp.-ECAPed specimen $(0.05)$.

Considering all the results, it is seen that the Exp.-ECAP process, which is applied by using the optimum die, offers higher mechanical properties than the ECAP process, and also causes a more homogeneous distribution in the average grain size, hardness values and strain values obtained in FE analysis. It is also observed that Exp.-ECAP passes applied after ECAP make the grain size and hardness distributions more homogeneous.

\section{Declarations}

\section{Ethical Approval}

Authors acknowledge that this study is original and has not been published elsewhere.

\section{Consent to Participate}

All authors confirm that they are involved to this study.

\section{Consent to Publish}

The authors confirm that the manuscript has been read and approved by all named authors.

\section{Authors Contributions}

All authors contributed to the study conception and design. Design of experiment was made by Serkan Öğüt and Assoc. Dr. Hasan Kaya. Material preparation, data collection, and analysis were performed by Serkan Öğ̈̈t under the supervision of Assoc. Dr. Hasan Kaya, Prof. Dr,.Aykut Kentli and Prof. Dr. Mehmet Uçar. The internal draft of the manuscript was written by Serkan Ögüt and all authors commented on previous versions of the manuscript. Assoc. Dr. Hasan Kaya and Prof. Dr. Aykut Kentli reviewed and edited the internal draft. All authors read and approved the final manuscript.

\section{Funding}

This work was supported by the Marmara University Scientific Research Project within the project number FEN-A-090217-0045.

\section{Competing Interests}

The authors declare that they have no conflict of interest.

\section{Availability of data and materials}

Not applicable

\section{References}

1. Edalati K, Horita Z (2016) A review on high-pressure torsion (HPT) from 1935 to 1988. Mater. Sci. Eng. A 652:325-352 
2. Nakao Y, Miura H (2011) Nano-grain evolution in austenitic stainless steel during multidirectional forging. Mater Sci Eng A 528:1310-1317 . https://doi.org/10.1016/j.msea.2010.10.018

3. Beygelzimer Y, Prilepo D, Kulagin R, Grishaev V, Abramova O, Varyukhin V, Kulakov M (2011) Planar Twist Extrusion versus Twist Extrusion. J Mater Process Technol 211:522-529 . https://doi.org/10.1016/j.jmatprotec.2010.11.006

4. Huang J, Zhu YT, Alexander DJ, Liao X, Lowe TC, Asaro RJ (2004) Development of repetitive corrugation and straightening. Mater Sci Eng A 371:35-39 . https://doi.org/10.1016/S09215093(03)00114-X

5. Shaarbaf M, Toroghinejad MR (2008) Nano-grained copper strip produced by accumulative roll bonding process. Mater Sci Eng A 473:28-33 . https://doi.org/10.1016/J.MSEA.2007.03.065

6. Iwahashi Y, Wang J, Horita Z, Nemoto M, Langdon TG (1996) Principle of equal-channel angular pressing for the processing of ultra-fine grained materials. Scr. Mater. 35:143-146

7. Özbeyaz K, Kaya H, Kentli A, Şahbaz M, Öğü S (2019) Mechanical properties and electrical conductivity performance of ECAP processed AA2024 alloy. Indian J Chem Technol 26:266269

8. Valiev RZ, Langdon TG (2006) Principles of equal-channel angular pressing as a processing tool for grain refinement. Prog Mater Sci 51:881-981 . https://doi.org/10.1016/j.pmatsci.2006.02.003

9. Faraji G, Mosavi Mashadi M, Kim HS (2011) Tubular channel angular pressing (TCAP) as a novel severe plastic deformation method for cylindrical tubes. Mater Lett 65:3009-3012 . https://doi.org/10.1016/j.matlet.2011.06.039

10. Lipinska M, Chrominski W, Olejnik L, Golinski J, Rosochowski A, Lewandowska M (2017) Ultrafine-Grained Plates of Al-Mg-Si Alloy Obtained by Incremental Equal Channel Angular Pressing: Microstructure and Mechanical Properties. Metall Mater Trans A Phys Metall Mater Sci 48:4871-4882 . https://doi.org/10.1007/s11661-017-4258-8

11. Şahbaz M, Kaya H, Kentli A (2020) A new severe plastic deformation method: thin-walled open channel angular pressing (TWO-CAP). Int J Adv Manuf Technol 106:1487-1496 . https://doi.org/10.1007/s00170-019-04748-1

12. Şahbaz M, Kentli A, Kaya H (2020) Performance of Novel TWO-CAP (Thin-Walled Open Channel Angular Pressing) Method on AA5083. Met. Mater. Int.

13. Sepahi-Boroujeni S, Fereshteh-Saniee F (2015) Expansion equal channel angular extrusion, as a novel severe plastic deformation technique. J Mater Sci 50:3908-3919. https://doi.org/10.1007/s10853-015-8937-9

14. Molodova X, Gottstein G, Winning M, Hellmig RJ (2007) Thermal stability of ECAP processed pure copper. Mater Sci Eng A 460-461:204-213 . https://doi.org/10.1016/j.msea.2007.01.042

15. Wu SD, Wang ZG, Jiang CB, Li GY, Alexandrov I V., Valiev RZ (2003) The formation of PSBlike shear bands in cyclically deformed ultrafine grained copper processed by ECAP. Scr Mater 48:1605-1609 . https://doi.org/10.1016/S1359-6462(03)00141-6

16. Guo T, Wei S, Wang C, Li Q, Jia Z (2019) Texture evolution and strengthening mechanism of single crystal copper during ECAP. Mater Sci Eng A 759:97-104. https://doi.org/10.1016/j.msea.2019.05.042

17. Han SZ, Goto M, Lim C, Kim CJ, Kim S (2007) Fatigue behavior of nano-grained copper prepared by ECAP. J Alloys Compd 434-435:304-306 https://doi.org/10.1016/j.jallcom.2006.08.179

18. Stepanov ND, Kuznetsov A V., Salishchev GA, Raab GI, Valiev RZ (2012) Effect of cold rolling 
on microstructure and mechanical properties of copper subjected to ECAP with various numbers of passes. Mater Sci Eng A 554:105-115 . https://doi.org/10.1016/j.msea.2012.06.022

19. Salimyanfard F, Reza Toroghinejad M, Ashrafizadeh F, Jafari M (2011) EBSD analysis of nanostructured copper processed by ECAP. Mater Sci Eng A 528:5348-5355. https://doi.org/10.1016/j.msea.2011.03.075

20. Alawadhi MY, Sabbaghianrad S, Huang Y, Langdon TG (2017) Direct influence of recovery behaviour on mechanical properties in oxygen-free copper processed using different SPD techniques: HPT and ECAP. J Mater Res Technol 6:369-377. https://doi.org/10.1016/j.jmrt.2017.05.005

21. Sepahi-Boroujeni S, Fereshteh-Saniee F (2015) The influences of the expansion equal channel angular extrusion operation on the strength and ductility of AZ80 magnesium alloy. Mater Sci Eng A 636:249-253 . https://doi.org/10.1016/j.msea.2015.03.073

22. Fereshteh-Saniee F, Sepahi-Boroujeni A, Sepahi-Boroujeni S (2016) Optimized tool design for expansion equal channel angular extrusion (Exp-ECAE) process using FE-based neural network and genetic algorithm. Int J Adv Manuf Technol 86:3471-3482 . https://doi.org/10.1007/s00170016-8487-6

23. Frint S, Hockauf M, Frint P, Wagner MFX (2016) Scaling up Segal's principle of Equal-Channel Angular Pressing. Mater Des 97:502-511 . https://doi.org/10.1016/j.matdes.2016.02.067

24. Kaya H, Uçar M, Cengiz A, Samur R, Özyürek D, Çalişkan A (2014) Novel molding technique for ECAP process and effects on hardness of AA7075. Mechanika 20:5-10. https://doi.org/10.5755/j01.mech.20.1.4207

25. Kaya H, Uçar M (2016) The Effects of Mechanical Properties on Fatigue Behavior of ECAPed AA7075. High Temp Mater Process 35:225-234 . https://doi.org/10.1515/htmp-2014-0193

26. Haghdadi N, Zarei-Hanzaki A, Abou-Ras D, Maghsoudi MH, Ghorbani A, Kawasaki M (2014) An investigation into the homogeneity of microstructure, strain pattern and hardness of pure aluminum processed by accumulative back extrusion. Mater Sci Eng A 595:179-187 . https://doi.org/10.1016/j.msea.2013.11.077

27. Öğüt S, Kaya H, Kentli A, Özbeyaz K, Şahbaz M, Uçar M (2021) Investigation of Strain Inhomogeneity in Hexa-ECAP Processed AA7075. Arch Metall Mater 66:431-436 . https://doi.org/10.24425/amm.2021.135875

28. Patil Basavaraj V, Chakkingal U, Prasanna Kumar TS (2009) Study of channel angle influence on material flow and strain inhomogeneity in equal channel angular pressing using 3D finite element simulation. J Mater Process Technol 209:89-95. https://doi.org/10.1016/j.jmatprotec.2008.01.031

29. Amani S, Faraji G, Abrinia K (2017) Microstructure and hardness inhomogeneity of fine-grained AM60 magnesium alloy subjected to cyclic expansion extrusion (CEE). J Manuf Process 28:197-208 . https://doi.org/10.1016/j.jmapro.2017.06.007

30. Chen B, Lu C, Lin D, Zeng X (2014) Microstructural evolution and mechanical properties of Mg 95.5Y3Zn1.5 alloy processed by extrusion and ECAP. Met Mater Int 20:285-290 . https://doi.org/10.1007/s12540-014-2025-6

31. Tao NR, Wang ZB, Tong WP, Sui ML, Lu J, Lu K (2002) An investigation of surface nanocrystallization mechanism in $\mathrm{Fe}$ induced by surface mechanical attrition treatment. Acta Mater 50:4603-4616 . https://doi.org/10.1016/S1359-6454(02)00310-5 


\section{Figures}

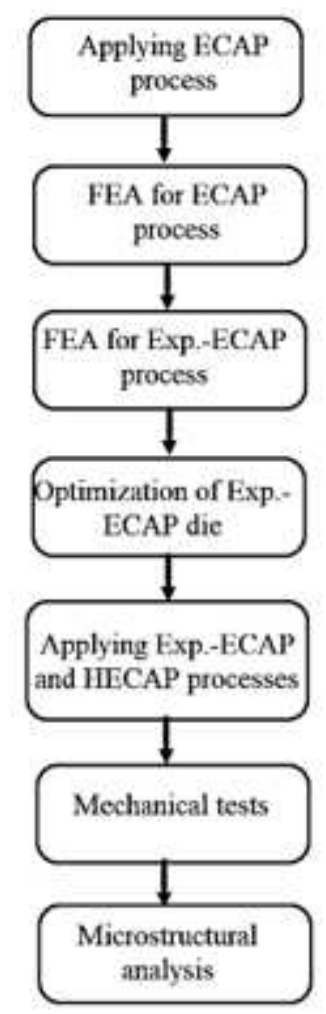

Figure 1

Flow chart of the methodology applied within the study

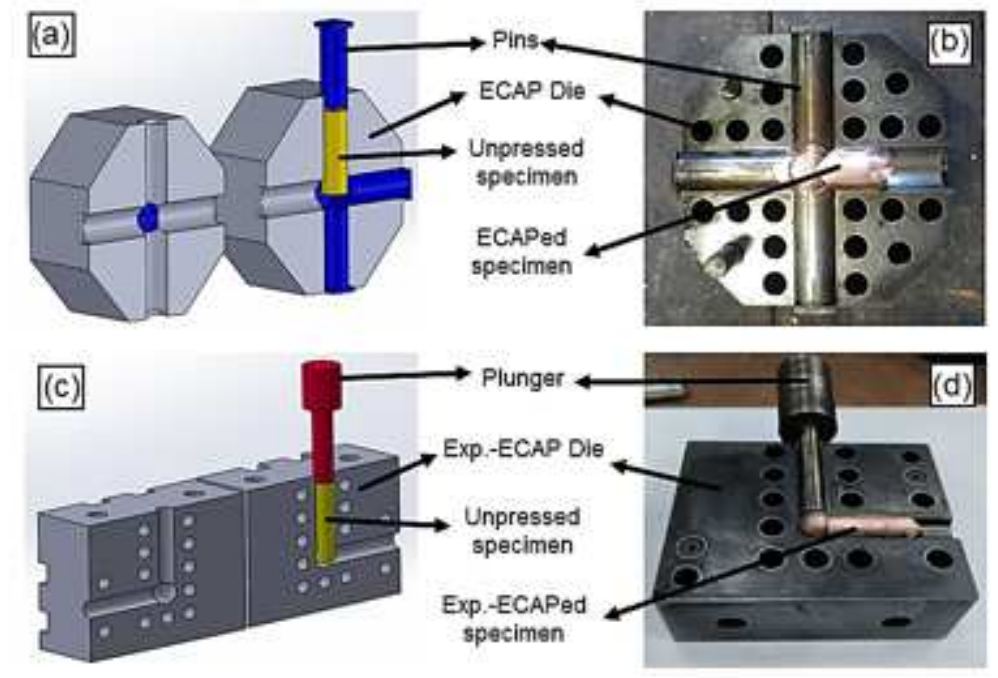

Figure 2

(a) ECAP die CAD geometry, (b) ECAP die and processed specimen, (c) Exp.- ECAP die CAD geometry, (d) Exp.-ECAPed die and processed specimen 


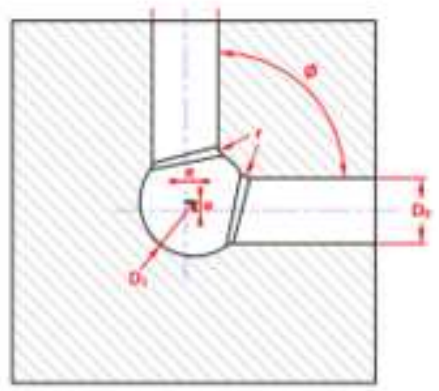

Figure 3

Geometrical parameters of Exp.-ECAP die

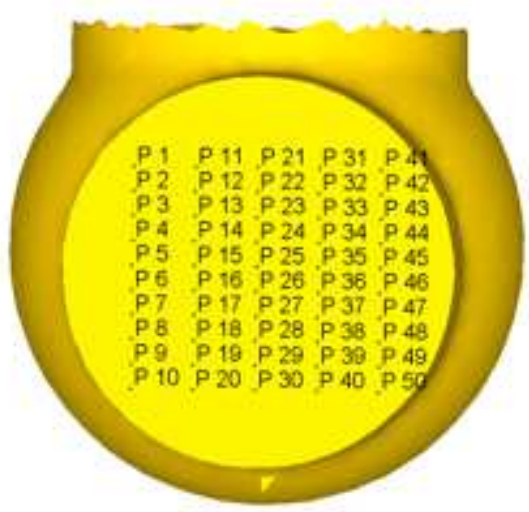

Figure 4

The pattern of the points used to extract effective strain values

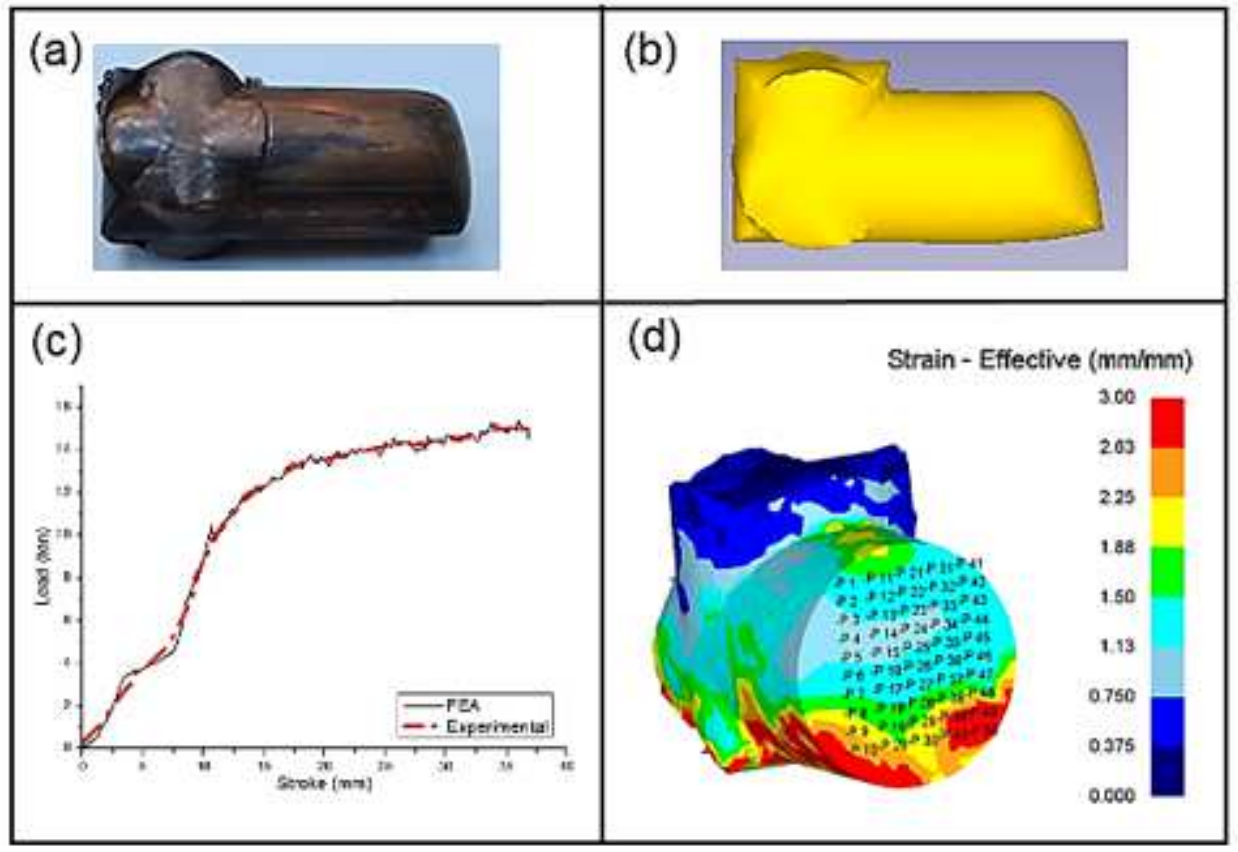

Figure 5 
(a) ECAPed specimen in the experiment, (b) ECAPed in FE analysis, (c) Load-stroke curves for ECAP process, (d) Numerical results for ECAP process

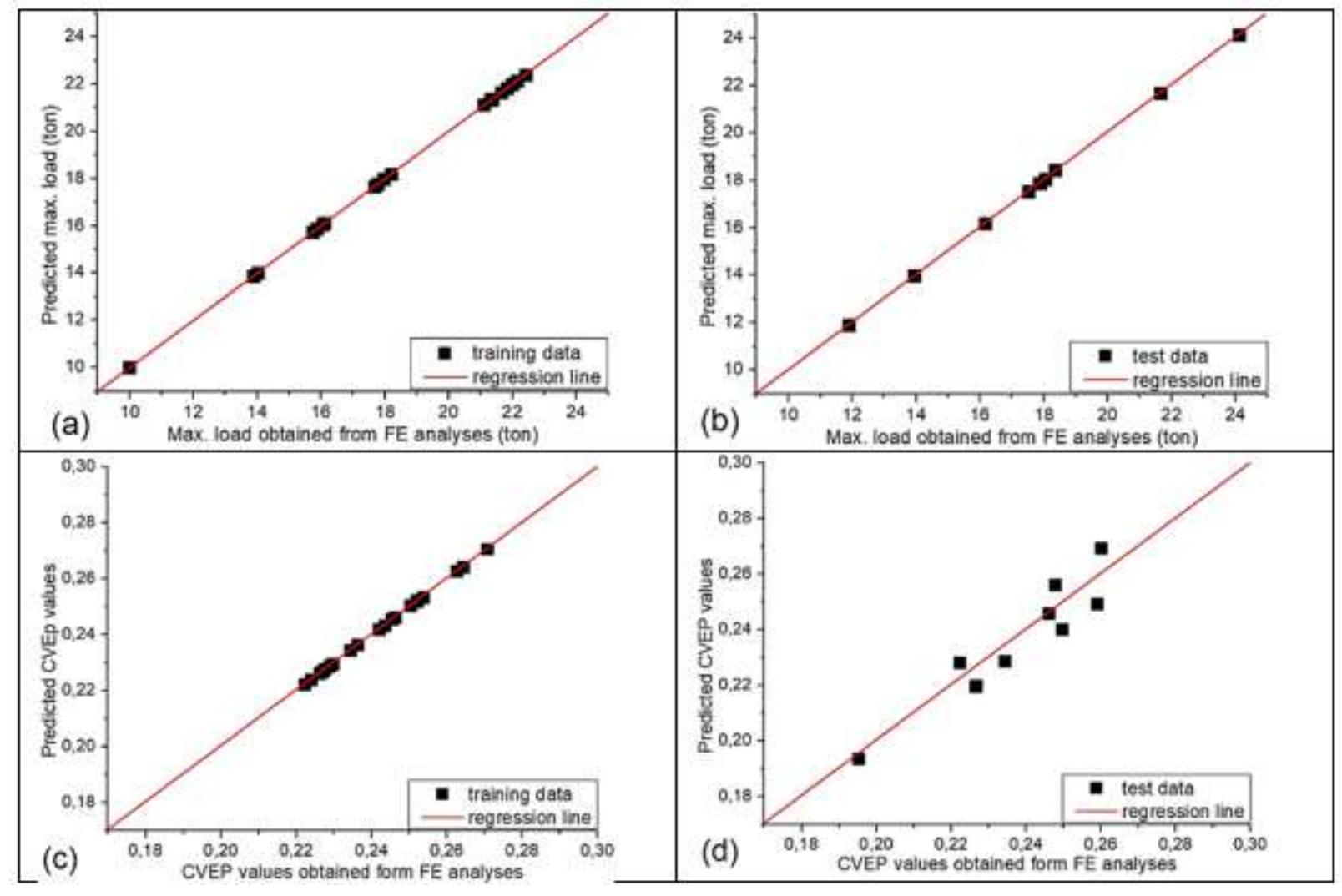

\section{Figure 6}

Predicted values vs FE analysis values for (a) training data of ML (maximum load) neural network, (b) test data of $M L$ neural network, (c) training data of $\triangle C V \varepsilon \llbracket \_p$ (coefficient of variance for plastic strain) neural network, (b) test data of $₫ \mathrm{CV} \varepsilon \mathbb{\square}$ p n neural network

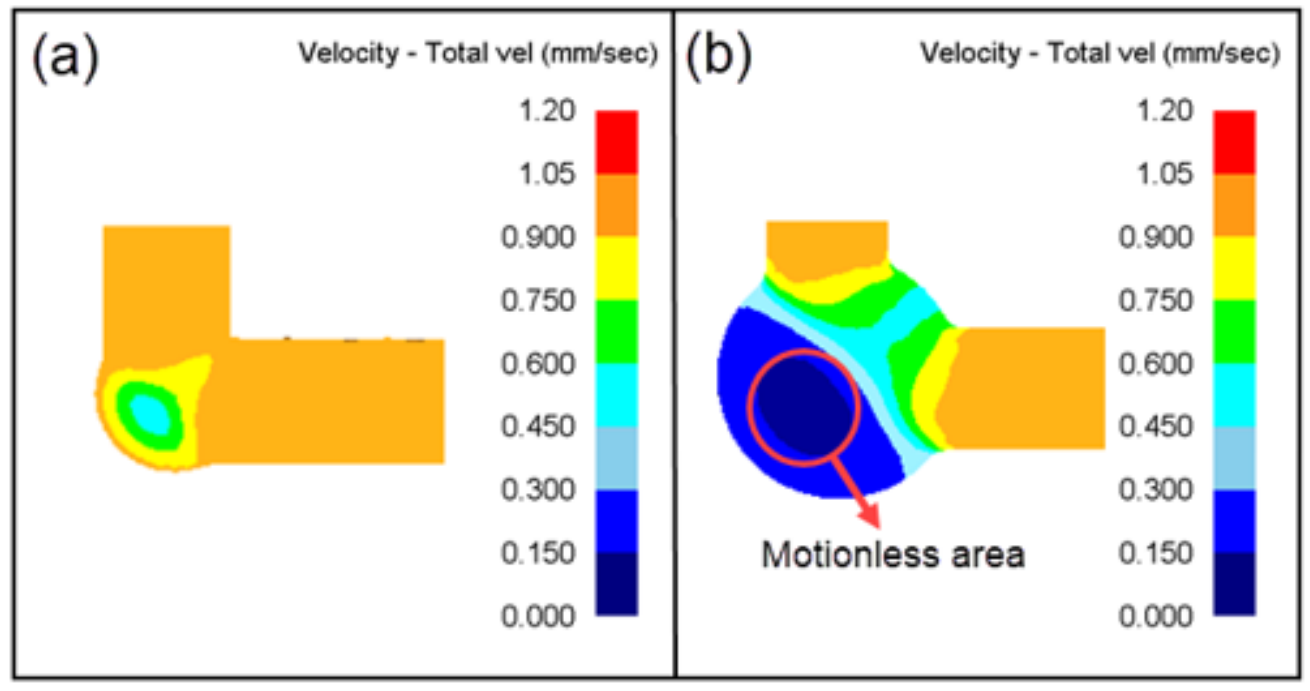

Figure 7

Total velocity distribution across the spherical cavity for (a) $a=0.8071$ and (b) $a=0.45$ 


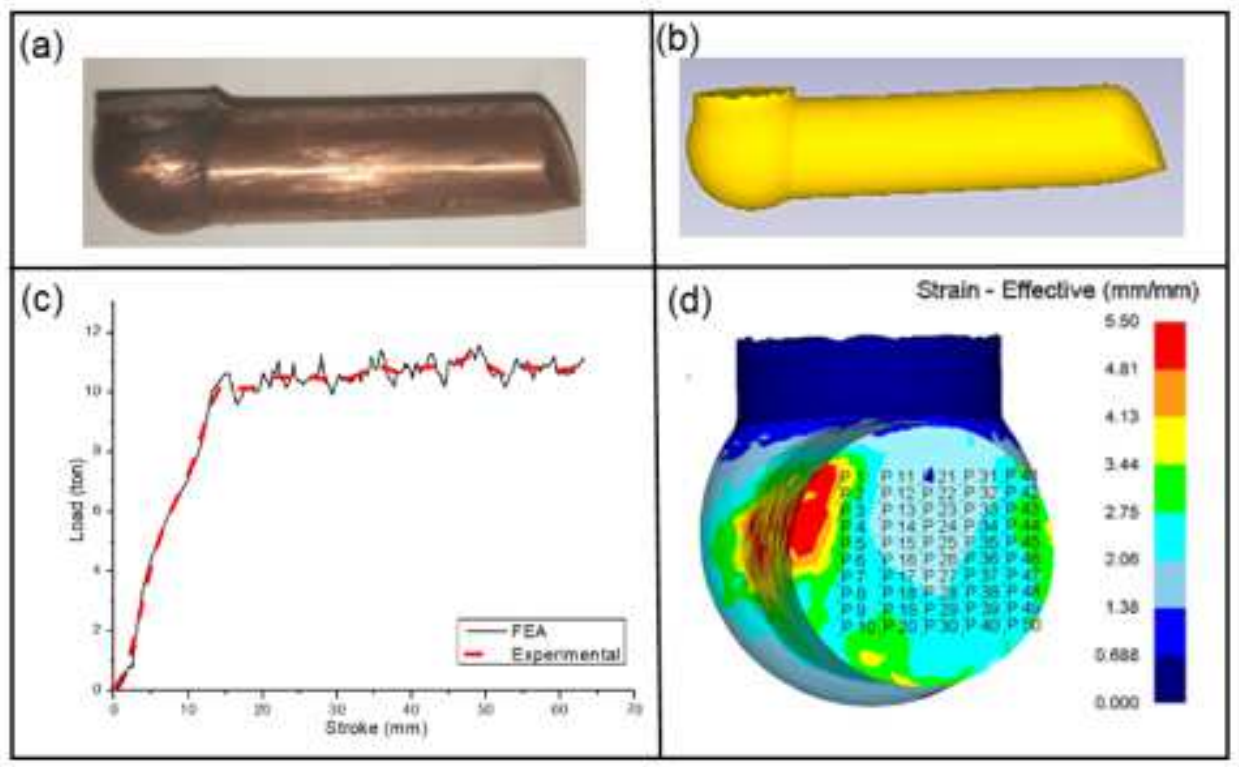

Figure 8

(a) Exp.-ECAPed specimen in experiment, (b) Exp.-ECAPed specimen in FE analysis, (c) Load-stroke curves for Exp.-ECAP process, (d) Numerical results for Exp.-ECAP process

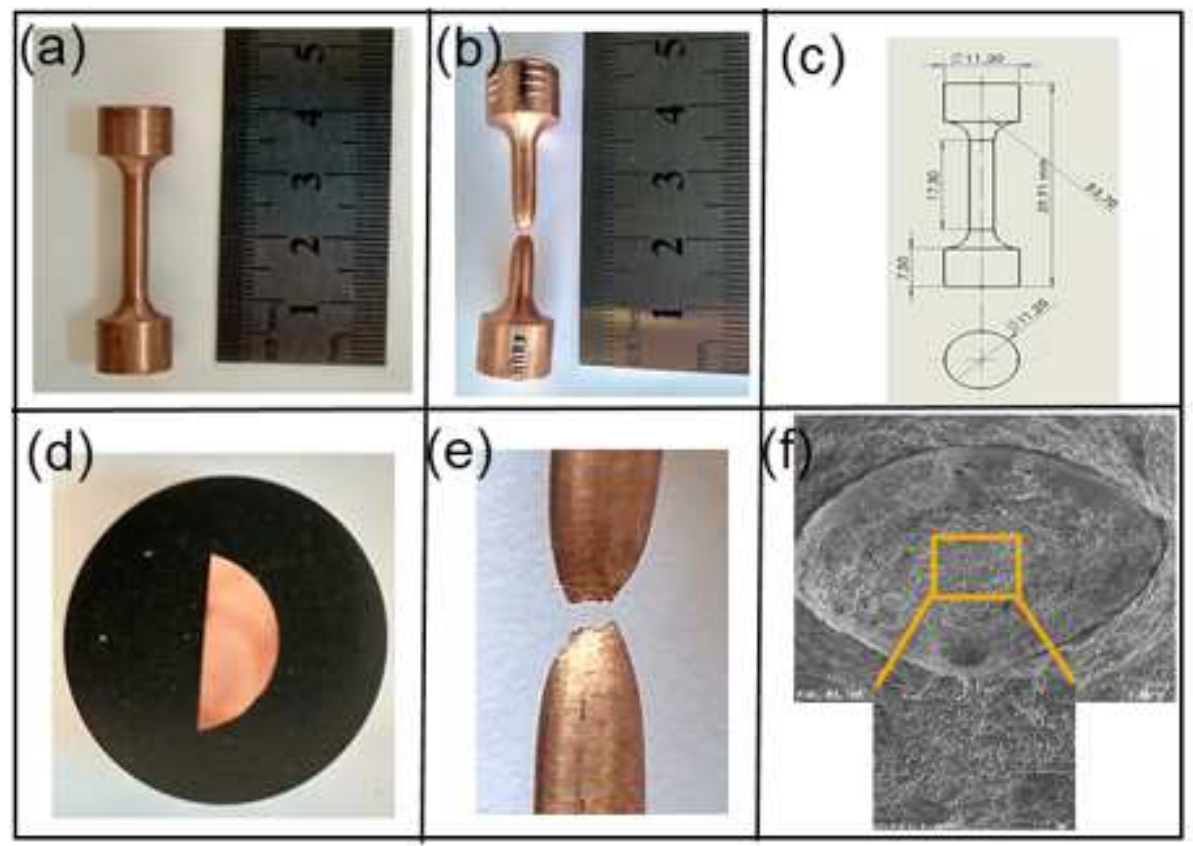

Figure 9

(a)Tensile test specimen, (b) fractured specimen after tensile test, (c) tensile test specimen dimensions,

(d) microstructure analysis and hardness test specimen, (e) fractured specimen (f) fracture surface and fractography 

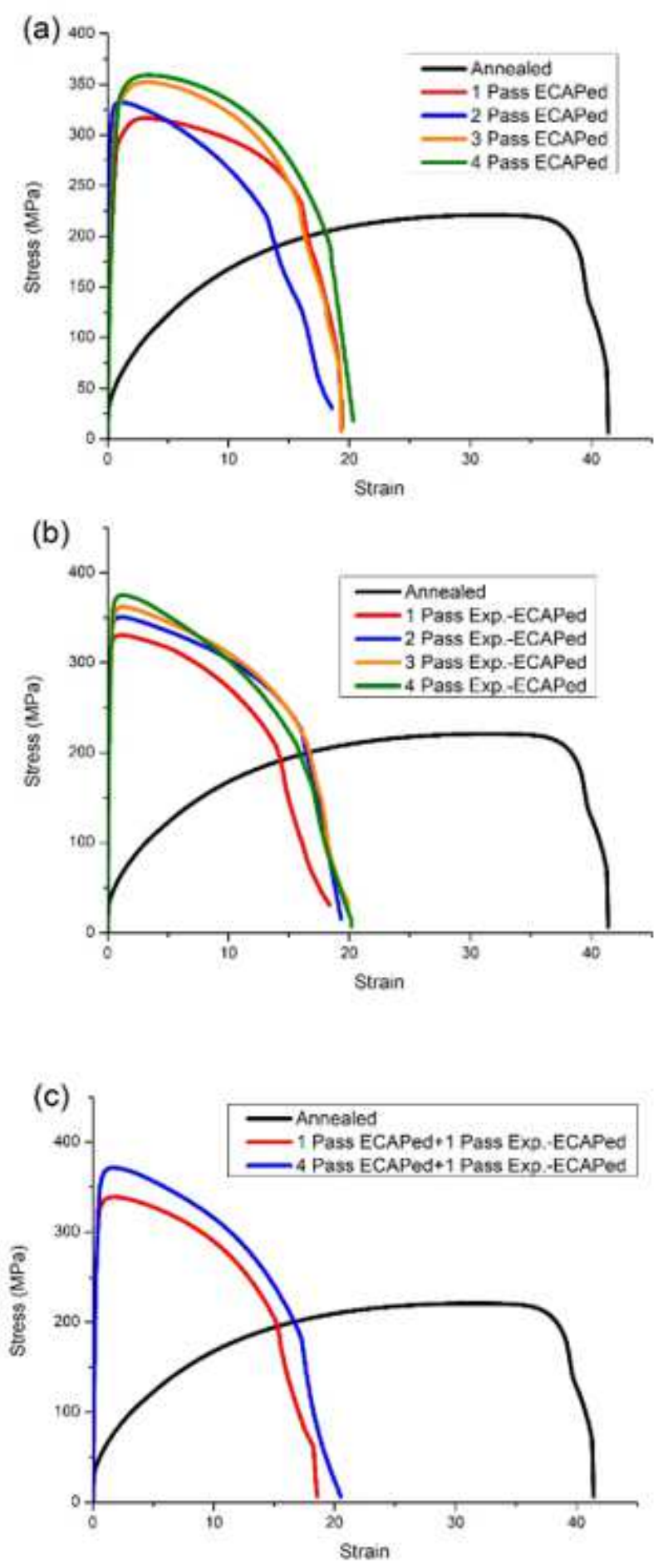

Figure 10

Stress-strain curves of (a) ECAPed, (b) Exp.-ECAPed and (c) Hybrid ECAPed specimens 

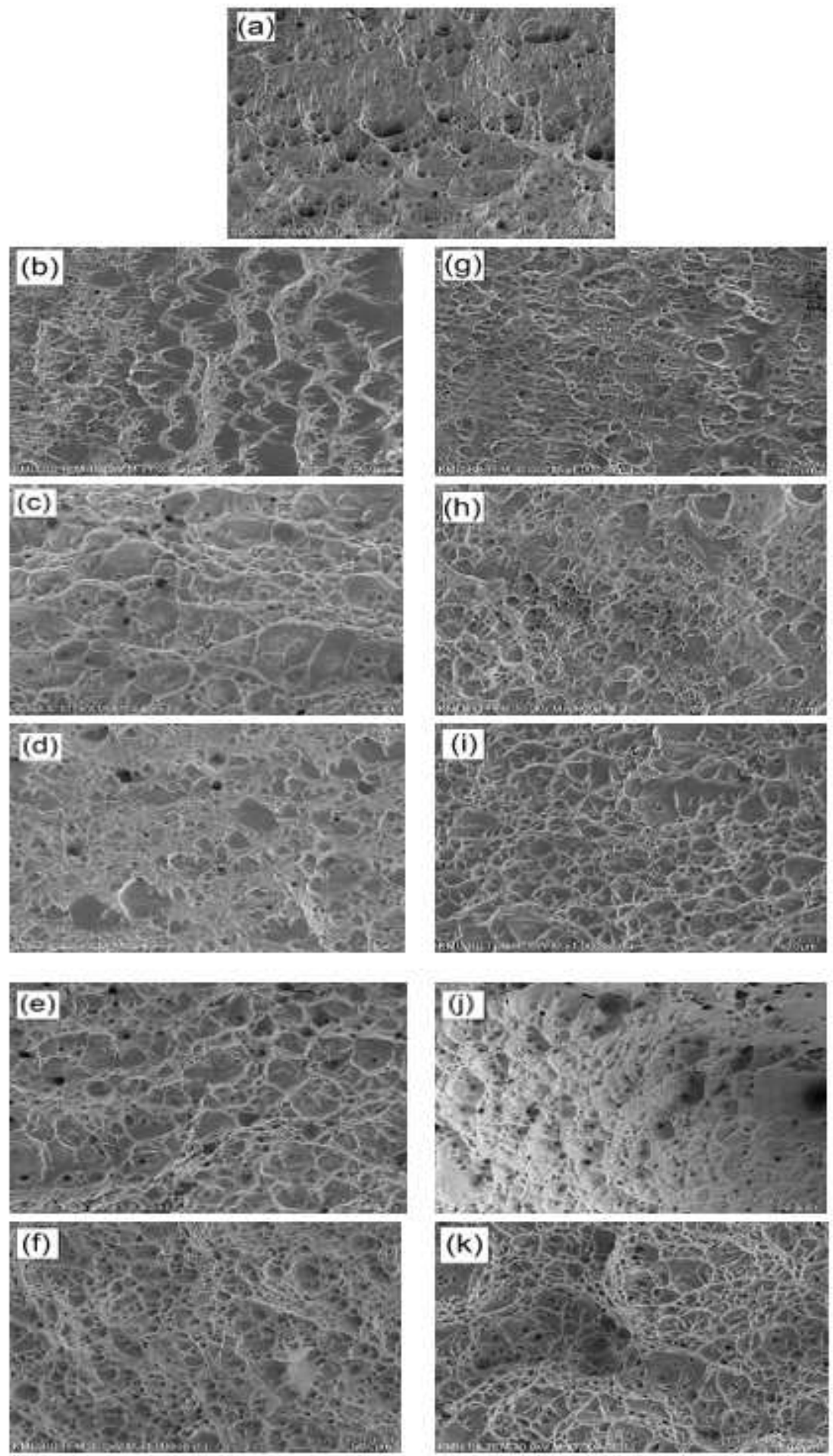

\section{Figure 11}

1000X Fractography images of (a) annealed, (b)-(e) 1-4 Pass ECAPed, (f)-(i) 1-4 Pass Exp.-ECAPed, (j)1 Pass ECAPed+1 Pass Exp.-ECAPed and (k) 4 Pass ECAPed+1 Pass Exp.-ECAPed pure copper specimens 


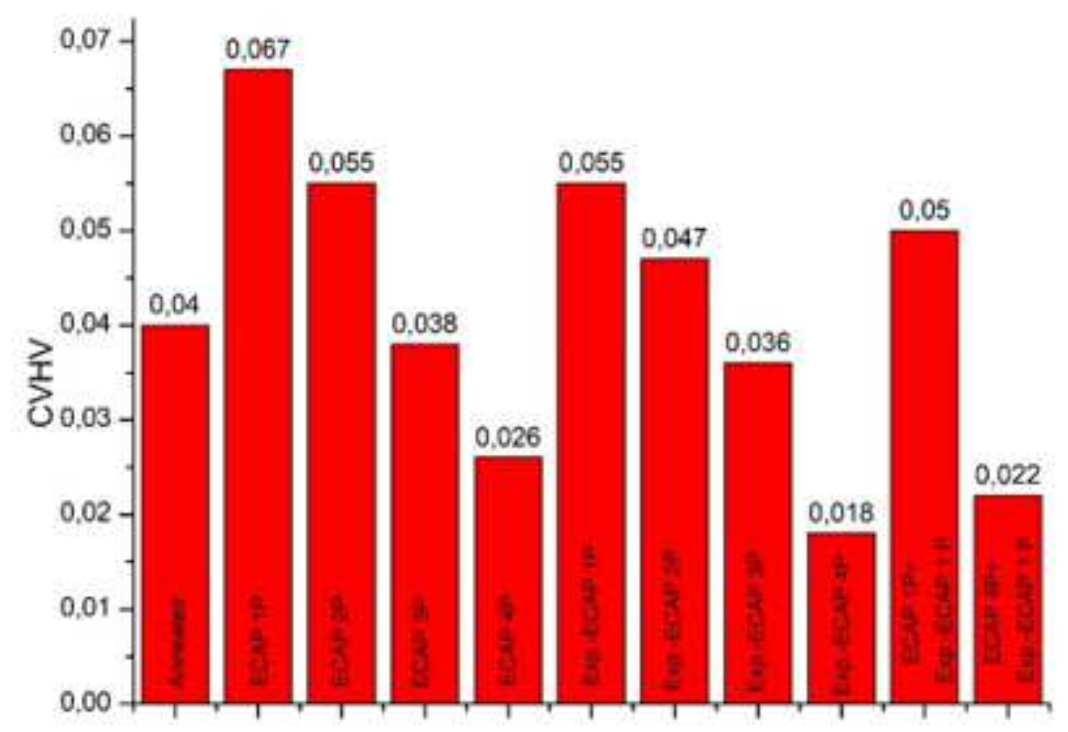

Figure 12

Coefficient of variance for hardness (CVHV) values of all specimens 

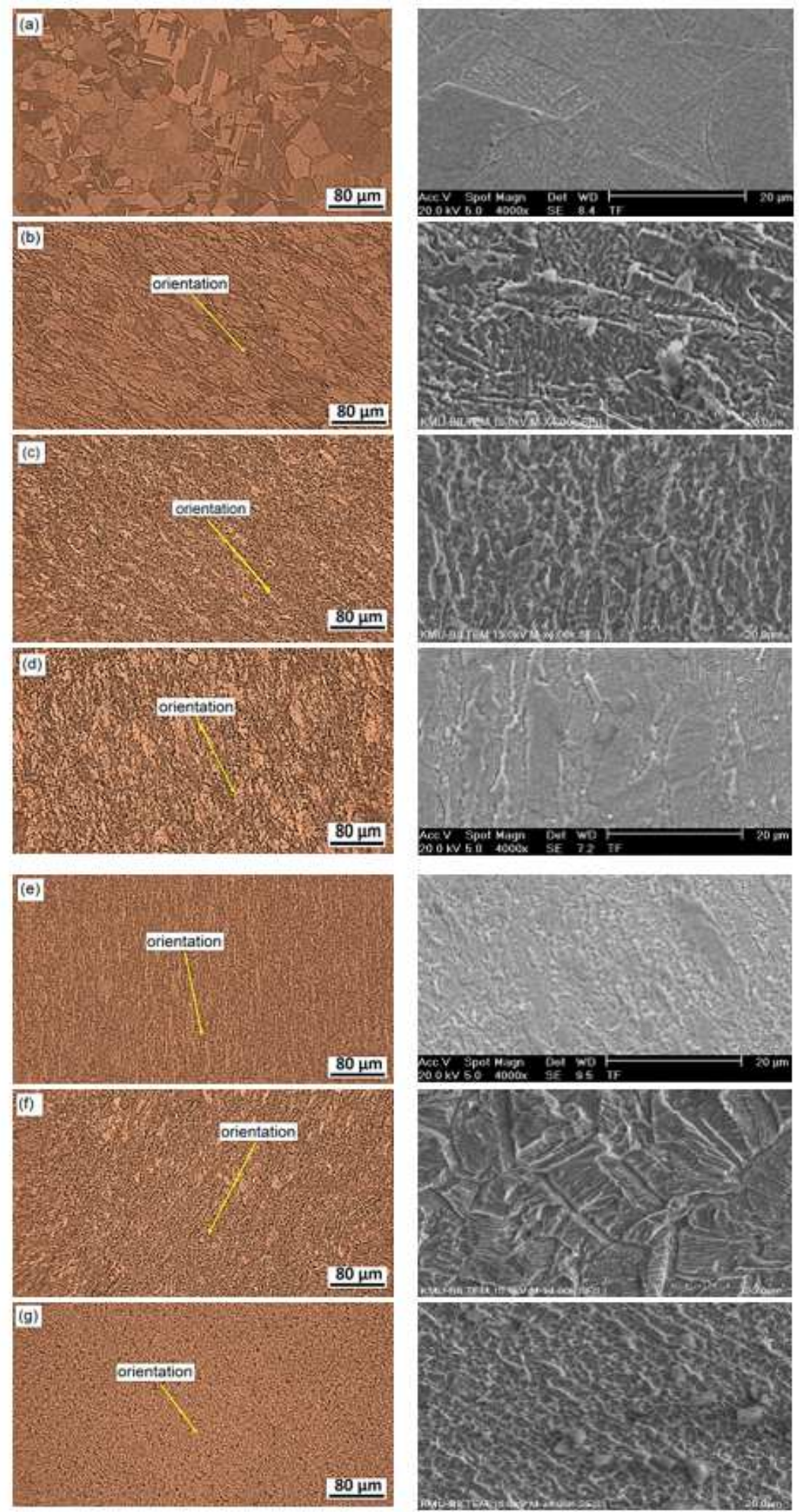

Figure 13

200X Optical microscope images (left) and SEM images (right) of (a) annealed, (b) 1 Pass ECAPed, (c) 4 Pass ECAPed, (d) 1 Pass Exp.-ECAPed, (e) 4 Pass Exp.-ECAPed (f) 1 Pass ECAPed +1 Pass Exp.-ECAPed and (g) 4 Pass ECAPed+1 Pass Exp.-ECAPed pure copper specimens 

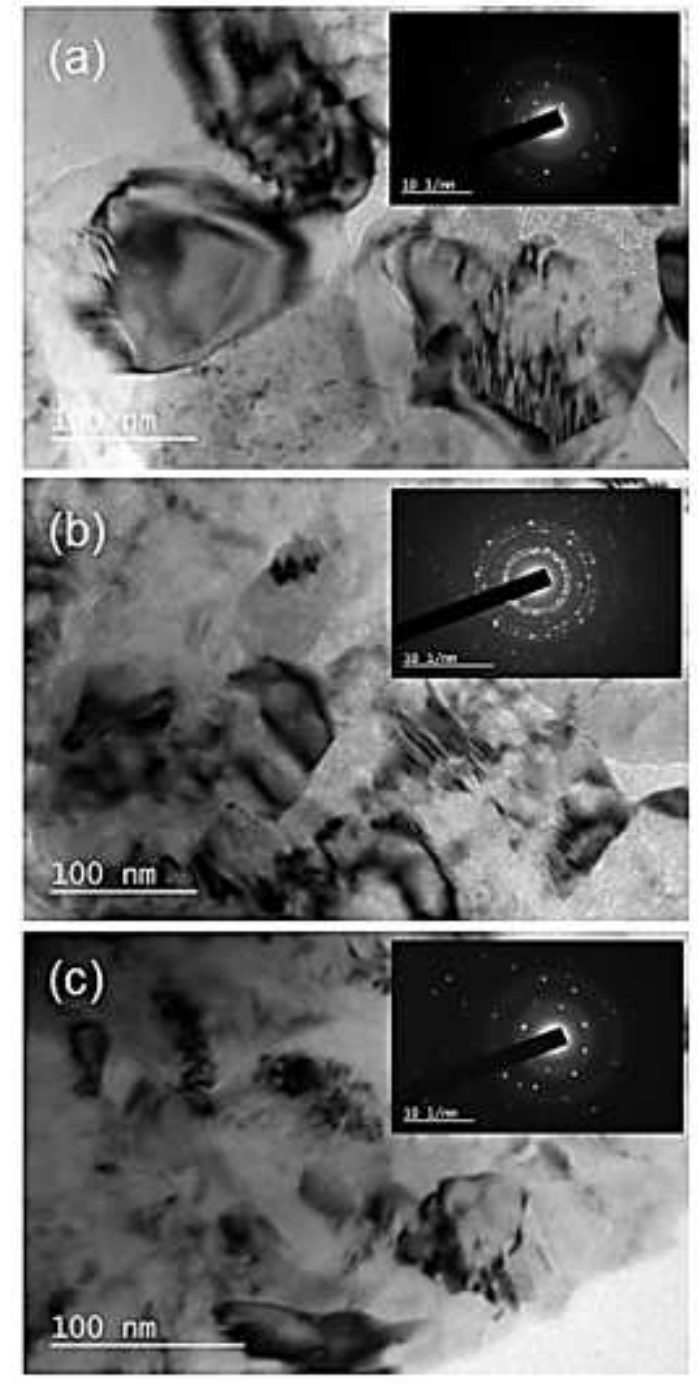

Figure 14

TEM images and SAED pattern of (a) 4 Pass ECAPed, (b) 4 Pass Exp.-ECAPed and (c) 4 Pass ECAPed +1 Pass Exp.-ECAPed pure copper specimens 

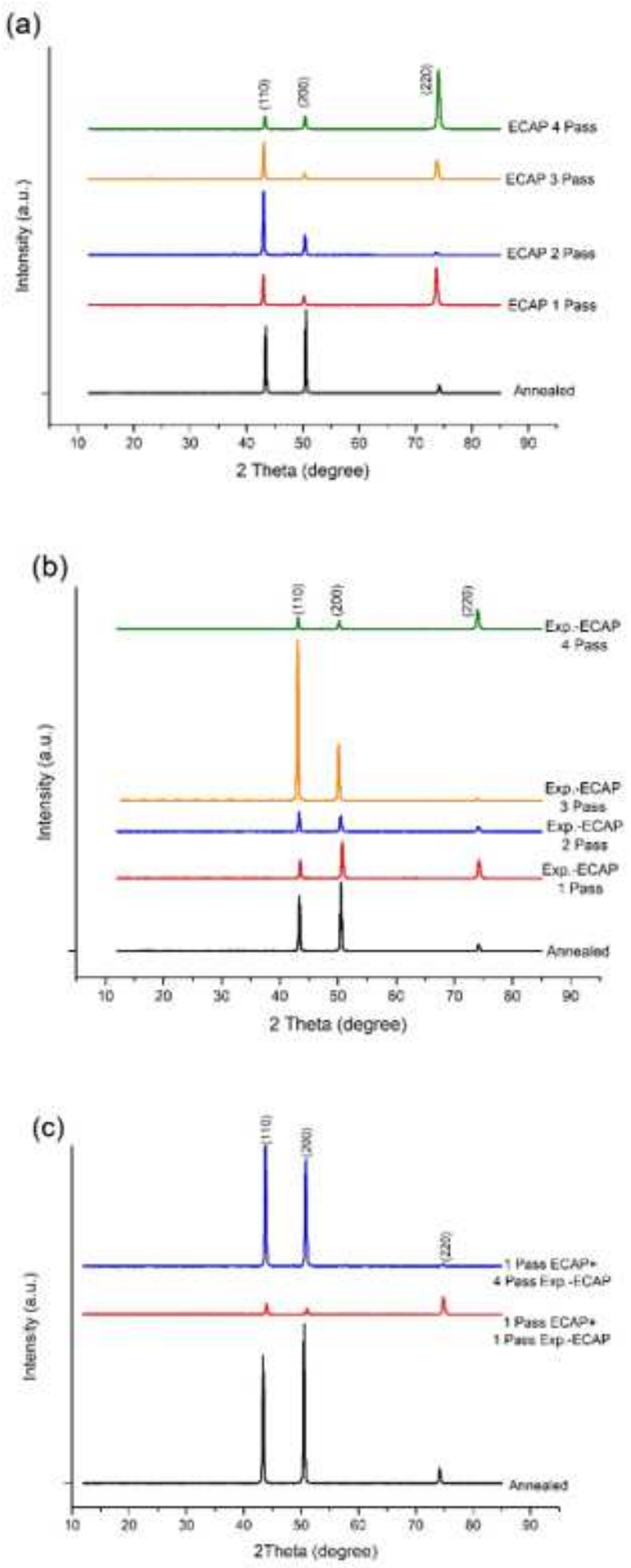

Figure 15

XRD patterns of pure copper specimens 